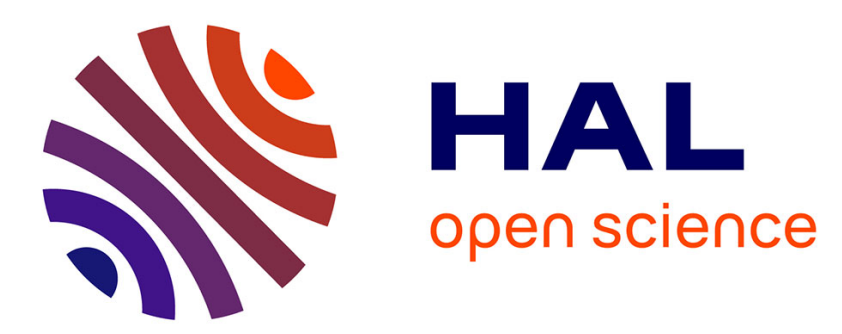

\title{
Interannual variability of surface currents in the tropical Pacific during 1987-1993
}

Claude Frankignoul, Fabrice Bonjean, Gilles Reverdin

\section{To cite this version:}

Claude Frankignoul, Fabrice Bonjean, Gilles Reverdin. Interannual variability of surface currents in the tropical Pacific during 1987-1993. Journal of Geophysical Research, 1996, 101, pp.3629-3648. 10.1029/95JC03439 . hal-00772211

\section{HAL Id: hal-00772211 \\ https://hal.science/hal-00772211}

Submitted on 11 Jan 2021

HAL is a multi-disciplinary open access archive for the deposit and dissemination of scientific research documents, whether they are published or not. The documents may come from teaching and research institutions in France or abroad, or from public or private research centers.
L'archive ouverte pluridisciplinaire HAL, est destinée au dépôt et à la diffusion de documents scientifiques de niveau recherche, publiés ou non, émanant des établissements d'enseignement et de recherche français ou étrangers, des laboratoires publics ou privés. 


\title{
Interannual variability of surface currents in the tropical Pacific during 1987-1993
}

\author{
Claude Frankignoul and Fabrice Bonjean \\ Laboratoire d'Océanographie Dynamique et de Climatologie, Université Pierre et Marie Curie, Paris
}

\section{Gilles Reverdin ${ }^{1}$}

Lamont-Doherty Earth Observatory, Columbia University, Palisades, New York

\begin{abstract}
Buoy drifts and current meter records between January 1987 and December 1993 are used to investigate the interannual variability of the equatorial Pacific currents at a depth of $15 \mathrm{~m}$. The sampling is coarse until mid-1988 but more complete afterward, so that the large-scale features of the anomaly currents can be documented on the seasonal to yearly timescale. Using objective analysis, bimonthly current anomalies are mapped between $20^{\circ} \mathrm{N}$ and $20^{\circ} \mathrm{S}$ on a $1^{\circ} \times 5^{\circ}$ grid, and the error covariance matrix of the analyzed fields are estimated. The current anomalies are primarily zonal, with largest amplitudes within about $8^{\circ}$ from the equator, and they are largely linked to the El Niño-Southern Oscillation phenomenon. In particular, broad, basin-wide westward anomaly currents were encountered during the 1988 La Niña, and strong eastward currents persisted from JulyAugust 1991 to January-February 1992, followed by westward currents from May-June to July-August 1992. An empirical orthogonal function (EOF) analysis shows that the first EOF of zonal current anomaly is largely uniform in the equatorial band, while the next two EOFs describe large-scale currents of opposite sign across the equator and across $160^{\circ} \mathrm{W}$, respectively. The EOFs are rather smooth and the errors on the principal component time series relatively small, which indicates that the sampling is adequate to describe the large-scale, low-frequency zonal current fluctuations. As the dominant EOFs of meridional current are noisy and the relative errors on the principal components larger, the meridional current fluctuations are not as well captured by the data set. Correlation analysis and a singular value decomposition are used to investigate the influence of advection by the large-scale, low-frequency currents on sea surface temperature (SST) anomalies during 1987-1993. Although the data set is noisy and other terms play an important role in the SST anomaly equation, the effect of zonal and, to a lesser extent, meridional advection is seen in much of the central and eastern equatorial Pacific. The dominant terms are the anomalous zonal advection of mean SST, the mean zonal, and, intermittently, meridional advection of SST anomalies.
\end{abstract}

\section{Introduction}

In most of the equatorial Pacific the evolution of the sea surface temperature is strongly affected by the oceanic circulation. The variability of the surface currents thus plays an important role in the El Niño-Southern Oscillation (ENSO) phenomenon, and its monitoring is crucial for understanding the physical processes that control the low-frequency changes in the sea surface temperature (SST) and the oceanatmosphere coupling. Wyrtki [1974] has estimated the fluctuations in the tropical Pacific zonal currents by monitoring sea level differences between several islands, suggesting, in particular, that the westward North Equatorial Current (NEC) and eastward North Equatorial Countercurrent (NECC) fluctuate synchronously and in opposition to the westward South Equatorial Current (SEC). Somewhat more accurate estimates of

\footnotetext{
'Now at Centre National de la Recherche Scientifique, Groupe de Recherches de Géodésie Spatiales, Toulouse, France.

Copyright 1996 by the American Geophysical Union.

Paper number 95JC03439.

0148-0227/96/95JC-03439\$05.00
}

the geostrophic current fluctuations have been derived from dynamic height calculations in regions with well-sampled temperature data. Considering the ship tracks that traverse nearly meridionally the central Pacific, Kessler and Taft [1987] and Taft and Kessler [1991] showed that the NEC varied little during Niños, while there were large changes in the NECC and, to a lesser extent, the SEC. During the 1972 and 1982-1983 El Niño warmings both the surface current and the volume transport indicated that the SEC became anomalously weak, while there was a large increase in the NECC, resulting in a west-east transfer of warm water. After the peak of the events the NECC nearly disappeared and the SEC reached a maximum. This pattern, however, was not marked in the moderate 1976 and 1986-1987 Niños. Picaut and Tournier [1991] gave refined estimates for the 1979-1985 period and found similar variations in the western Pacific. The surface geostrophic flow fluctuations can also be estimated with a more global coverage from altimeter height anomalies, and Delcroix et al. [1991] and Picaut and Delcroix [1995] found evidence in the along-track Geosat sea level data of equatorial wave propagation during the 1986-1989 period.

In the above studies, only the surface geostrophic flow could 
be estimated from the oceanic observations. However, the ageostrophic, frictionally controlled currents are generally larger near the surface, and, at least away from the equator, they dominate the near-surface currents [e.g., Wijffels et al., 1994]. The Ekman component could, in principle, be derived from wind stress observations, but the vertical shear of the ageostrophic current and its rate of rotation with depth is poorly documented, and the Pacific wind stress remains inaccurately known, albeit to a lesser extent since the deployment of the Tropical Ocean and Global Atmosphere (TOGA) Tropical Atmosphere Ocean (TAO) array [Hayes et al., 1991a]. Hence direct measurements are needed to estimate the nearsurface currents. Long time series of horizontal current have been obtained from current meters at a few mooring sites located along the equator, showing intraseasonal fluctuations and a marked interannual variability associated with ENSO [e.g., Halpern, 1987; McPhaden and Hayes, 1990; McPhaden et al., 1990]. In particular, an anomalous eastward advection in the surface layer was observed during the El Niño events. In the western Pacific there was a reversal of the SEC during westerly wind bursts and during periods of sustained westerlies, causing large eastward displacements of warm surface water along the equator. Occasional reversals of the SEC were also seen in the eastern Pacific during the passage of the Kelvin waves forced by the western Pacific westerly wind bursts.

Although the current meter data are highly accurate and provide precious information on the high-frequency fluctuations and the current shear, they are limited to a few locations and give little information on the spatial patterns of the surface currents. A broader coverage is provided by the satellitetracked drifting surface buoys that have been deployed in the tropical Pacific since the late 1970s, but the sampling was limited at first. More drifters began to be launched in 1986, and after mid-1988 the number of drifters increased greatly, providing an acceptable sampling in most of the tropical Pacific, except near the equator, because the mean current has a strong divergence near the equator that tends to create data void regions [Poulain, 1993]. A combination with the mostly equatorial moored data can compensate for the low equatorial sampling, however. Thus merging the two data sets for the period January 1987 to April 1992, Reverdin et al. [1994] estimated the horizontal current at a depth of $15 \mathrm{~m}$, which corresponds to the level of the current that is followed by most drifters, and investigated the mean seasonal variability of the equatorial Pacific currents between $20^{\circ} \mathrm{N}$ and $20^{\circ} \mathrm{S}$. Here we consider the interannual variability of the horizontal current in this data set, which has been extended to December 1993, although for consistency with Reverdin et al. [1994] the anomalies are calculated with respect to the January 1987 to April 1992 mean seasonal cycle. The 1987-1993 period contains the end of the 1986-1987 El Niño, the strong 1988 La Niña, and the 1991-1992 El Niño, whence the anomalous displacements of water masses during these events can be documented, even though the data distribution is often gappy and does not really allow the full resolution of the anomaly currents before the end of 1988.

To map the space-time yariability of the surface current anomalies, we use objective analysis. Because of the limited sampling, only bimonthly anomalies are considered, which strongly filters the 20- to 30-day instability waves [e.g., Halpern et al., 1988]. For simplicity, the analysis is done in the spatial domain for each bimonthly period separately. Some smoothing is then done in the time domain, so that the time resolution is too coarse for resolving Kelvin wave propagation (a first baroclinic mode propagates through $120^{\circ}$ longitude in 2 months), barely adequate for Rossby waves, but well-adapted to the ENSO variability. The full error covariance matrix of the analyzed fields is also calculated, so the accuracy of the analyzed fields can be assessed, and the data can be used for tropical ocean model testing [Frankignoul et al., 1989].

Because of the large zonal gradients of the SST field in the equatorial Pacific, it has often been suggested that anomalous advection largely contributes to SST changes. Using a simple wave model to explain the observed SST changes from sea level observations, Gill [1983] showed that the warm SST anomalies seen in the central Pacific during the 1972 El Niño resulted from a huge anomalous eastward advection of warm water lasting about a year, while near the eastern boundary, anomalous poleward advection and upwelling were likely to be more important. Harrison and Schopf [1984] stressed the dependence of zonal advection by Kelvin waves on the mean SST gradients and the resulting seasonal dependence of the advective effects, while Seager [1989] showed that, in his simple tropical model, zonal advection played an important role in the central Pacific, but upwelling was more efficient in the eastern Pacific. A linear, two-layer reduced gravity model was used by Kawabe [1994] to suggest that the rate of temperature changes almost balanced the zonal SST advection by Kelvin and Rossby waves between $170^{\circ} \mathrm{W}$ and $110^{\circ} \mathrm{W}$, while east of $105^{\circ} \mathrm{W}$, the zonal advection was opposite in sign to the SST changes and entrainment of deeper water dominated the SST equation. Using in situ currents [McPhaden and Picaut, 1990] and Geosat-derived currents [Picaut and Delcroix, 1995], it has been shown that the zonal displacement of the eastern edge of the western Pacific warm pool was primarily due to advection by zonal current anomalies during the 1986-1987 El Niño and the 1988 La Niña.

The role of advection has also been investigated in oceanic general circulation models (GCMs). Harrison et al. [1990] found in the Geophysical Fluid Dynamic Laboratory (GFDL) GCM that the major central Pacific warming during the 19821983 El Niño occurred primarily from anomalous eastward advection of warm water, while, farther east, eastward advection remained significant but meridional advection was also important. The 1983 cooling, however, was initiated by vertical advection and mixing, and horizontal advection was not important at first. However, Harrison et al. [1990] found the dominant physics at the equator to be somewhat a function of the wind stress data used in the simulations, so that the forcing uncertainties may obscure the model results. The dominant physics are also model-dependent, since Barnett et al. [1991] found in a Max Planck Institute für Meteorologie (MPI) GCM that meridional advection (primarily due to anomalous Ekman currents) dominated the heat balance in all the tropical Pacific, except right at the equator, where all the terms contributed. The model dependence of SST anomaly dynamics has been discussed by Miller et al. [1993], who found different balances of terms in different tropical Pacific models, although zonal advection always tended to be dominant west of the dominant SST anomalies, meridional advection north and south of their peak, and upwelling and vertical mixing on their eastern flank.

In view of the dependence of the results on both the oceanic model and the atmospheric forcing data, it is of interest to quantify the relative contribution of zonal and meridional advection to the SST anomaly changes, using solely observations. Some studies have used the equatorial moored array data. In 
particular, Hayes et al. [1991b] studied the surface mixed layer heat budget along $110^{\circ} \mathrm{W}$ during 1986-1988. Although no single process dominated the SST changes and many terms in the heat balance were important, there was little correlation between mixed layer heating and zonal temperature advection and only some evidence of meridional advection effects. However, the spatial resolution was poor and the duration of the measurements limited. Using a more complete data set at $140^{\circ} \mathrm{W}$, Kessler and McPhaden [1995] suggested that the largest SST anomaly variations during 1991-1993 could be ascribed to upwelling and that horizontal advective mechanisms were only important at certain times.

In this paper we analyze the effects of horizontal advection on the low-frequency SST anomaly variability in the tropical Pacific, using our surface current estimates and the SST data of Reynolds and Smith [1994]. Again, we consider the 1987-1993 period, although the surface currents are noisy at the beginning of the period and there are large gaps near the equator in 1993. However, we restrict the analysis to a somewhat smaller portion of the tropical Pacific where regions which are generally poorly sampled have been eliminated. Note that only the large spatial and temporal scales can be resolved by the analysis and that we do not consider other important terms in the nearsurface heat budget, like vertical advection, eddy heat flux, and surface heat exchanges. Thus we do not expect even a rough balance between SST anomaly rate of change and anomalous horizontal advection.

The paper is organized as follows. In the next section we present the buoy drifts and the mooring currents and recall how they were merged and how the seasonal cycle was estimated. Our version of objective analysis is described in section 3 , and the main features of the observed current anomalies and their dominant spatial patterns of variability are discussed in section 4. The effects of horizontal advection on SST anomaly changes are investigated in section 5 , and a summary is given in section 6 .

\section{Data}

\subsection{Drifters}

The data used in this analysis were obtained from drogued surface drifters and moored current meters deployed in the equatorial Pacific during the period January 1987 to December 1993. The data and data handling are described by Reverdin et al. [1994] (hereinafter referred to as REV); and only a summary is given here.

The drifters typically have a surface float linked by a loose tether to a subsurface float at $4 \mathrm{~m}$ and a drogue centered at 15 $\mathrm{m}$. They were tracked by satellite with the Argos system, with rms positioning errors of less than a few hundred meters. There are typically five to eight satellite fixes per day, and the raw positions were constructed at 6-hourly intervals with a krieging algorithm [Hansen and Herman, 1989]. As most buoys were only emitting 1 day out of 3 , daily averaged velocities reported at midday were used. The number of drift days greatly increases after mid-1988. The data density varies somewhat in time and space, and large areas can be poorly sampled at times. Also, the drifter density can be small at the equator because of the meridional divergence of the surface currents [Poulain, 1993].

Calibration experiments [e.g., Niiler et al., 1987] suggest that the drifts of the drogued buoys are within a few centimeters per second of the currents at $15 \mathrm{~m}$ and that the difference can be modeled, knowing the buoy characteristics, the wind, and the current shear. This error can be coarsely modeled by 0.003 $W$, where $W$ is the wind velocity at $10 \mathrm{~m}$, and it was corrected for in the daily currents, using monthly pseudostress field derived from ship and buoy measurements by Legler and $O$ 'Brien [1985] to estimate $W$. Typically, the correction does not exceed $3 \mathrm{~cm} \mathrm{~s}^{-1}$.

Nearly $30 \%$ of the drifter data considered here (but only $10 \%$ near the equator) were reported as having lost their drogue. Although undrogued buoys could have an additional downwind drift of the order of $10 \mathrm{~cm} \mathrm{~s}^{-1}$, no correction was attempted because, in practice, some of the drogue loss reports are uncertain; for example, $\mathbf{4 1}$ buoys in the western Pacific for which drogue loss was reported were not equipped with a drogue-loss sensor. The averaged downwind error resulting from the inclusion of undrogued buoys should range between $1 \mathrm{~cm} \mathrm{~s}^{-1}$ near the equator and $5 \mathrm{~cm} \mathrm{~s}^{-1}$ poleward of $10^{\circ} \mathrm{N}$, $10^{\circ} \mathrm{S}$. This is within the range of current errors associated with deviations of the drogue center from its nominal depth and well below sampling errors. Note that REV was not able to distinguish the seasonal currents estimated from all the buoys from those using only buoys reported with their drogue.

Since the currents have a much longer zonal than meridional scale, except near the continents, the daily velocity data were binned into monthly means on a $1^{\circ} \times 5^{\circ}$ latitude $\times$ longitude grid. To better represent the meridional current structure, the equator is a boundary between grid boxes.

\subsection{Moored Current Meters}

Velocity measurements were also obtained from current meter moorings located along the equator at $110^{\circ} \mathrm{W}, 140^{\circ} \mathrm{W}$, $170^{\circ} \mathrm{W}, 165^{\circ} \mathrm{E}$, and at $7^{\circ} \mathrm{N}, 140^{\circ} \mathrm{W}$ [McPhaden and McCarty, 1992; McCarty and McPhaden, 1993; R. Weisberg, personal communication, 1994]. The equatorial moorings at $110^{\circ} \mathrm{W}$, $140^{\circ} \mathrm{W}$, and $165^{\circ} \mathrm{E}$ were available for the whole period until September, October, and December 1993, respectively. At $170^{\circ} \mathrm{W}$ the data were from May 1988 until December 1993 and at $7^{\circ} \mathrm{N}, 140^{\circ} \mathrm{W}$, from June 1988 to April 1991 . Typically, the 15-m horizontal current was estimated by linear interpolation between the two closest levels (10 to $25 \mathrm{~m}$ in some cases, but also 3 to $25 \mathrm{~m}$ and 10 to 45 or $50 \mathrm{~m}$ ). When data at one level were missing, an averaged shear was added to the other record, which should not introduce a rms error larger than $5 \mathrm{~cm} \mathrm{~s}^{-1}$ in the monthly currents. At the $170^{\circ} \mathrm{W}$ mooring, which had all upward looking Doppler profiler located at $250 \mathrm{~m}$ depth, the shallowest reliable data were centered at $30 \mathrm{~m}$, so it was assumed that the shear between 15 and $30 \mathrm{~m}$ is the same as between 30 and $40 \mathrm{~m}$.

The high-frequency variability of the moored velocity time series is large, in particular, along the equator at $110^{\circ} \mathrm{W}$ and $140^{\circ} \mathrm{W}$, with an integral timescale of about 3 days for the zonal component $u$ and 2 days for the meridional component $v$. To blend the moored data with the drifter currents, the current meter records were divided into daily means.

\subsection{The Blended Product}

REV have shown from an investigation of close-by currents from moorings and drifters that there might be a systematic bias with stronger drifter currents but that it is usually less than $10 \mathrm{~cm} \mathrm{~s}^{-1}$ and often small compared to the sampling errors. Thus the two data sets were merged without further correction. Since the drifter data are sparse within $1^{\circ}$ of the equator, because of the equatorial divergence, more importance was 


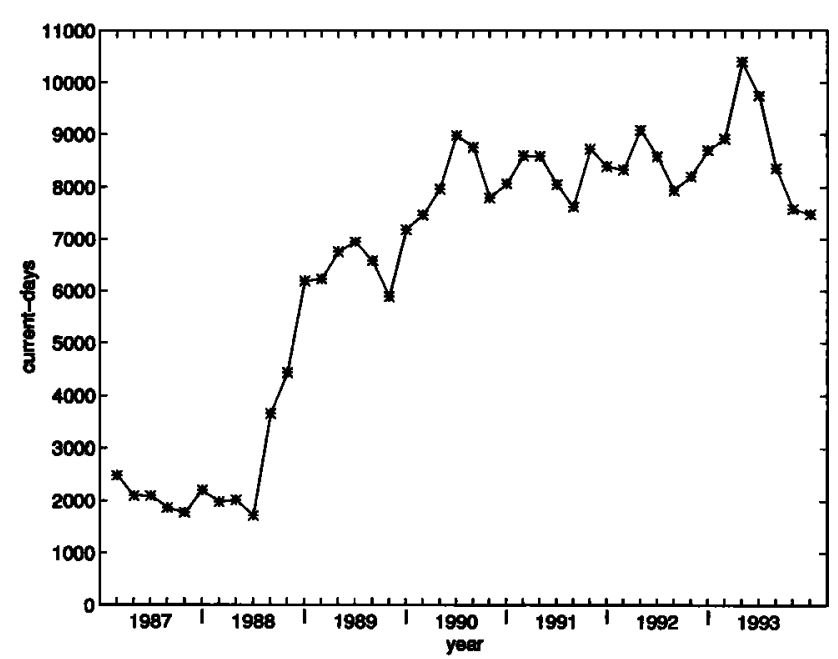

Figure 1. Distribution in time of the total number of current days per bimonthly period used for the analysis within $20^{\circ} \mathrm{N}$ and $20^{\circ} \mathrm{S}$ in the equatorial Pacific Ocean.

given to the current meter data in the blended product by choosing the grid so most equatorial moorings would be centered between four adjacent $1^{\circ} \times 5^{\circ}$ grid boxes and distributing the moored data equally between the boxes. This artificially increases the apparent spatial coverage of the observations but does alter the number of independent data.

Because of the large level of high-frequency fluctuations, monthly mean velocities were only calculated at $1^{\circ} \times 5^{\circ}$ boxes with at least 5 days of data for $u$ and 3 days for $v$. Their error was simply estimated by dividing the monthly variance by an effective number of independent samples per month, which was crudely taken as the number of current days divided by 5 for $u$ and 3 for $v$. Figure 1 shows the total number of current days per bimonthly period for the zonal velocity. Although it is slightly larger for the meridional velocity, the sampling is too small to resolve the current anomalies on a monthly basis, except in a few areas, and a bimonthly resolution is used below.

\subsection{Mean Seasonal Cycle}

The construction of a mean seasonal cycle for the period between January 1987 and April 1992 is described in REV. The seasonal cycle was constructed by using a function-fitting algorithm, which interpolates and smoothes the monthly velocities zonally (the function is a straight line defined over five grid points centered at the longitude of interest) but not meridionally, and only keeps the yearly mean and the annual and semiannual harmonics. The fitting was done for each year by least squares and the monthly velocities weighted by their accuracy. The January 1987 to April 1992 mean seasonal cycle was then estimated by averaging, taking into account the accuracy of each year's estimates. Because of the zonal uniformity of the currents in the tropical Pacific, the mean velocity is well resolved in most regions. However, the smoothing procedure is inadequate near the boundaries. In particular, finer zonal resolution would be needed to represent correctly the Mindanao Current, as in the work by Lukas et al. [1991].

\subsection{Velocity Aromalies}

The mean seasonal cycle was subtracted from the (gappy) monthly data, and bimonthly velocity anomalies with respect to the January 1987 to April 1992 monthly climatology were constructed at each grid point by averaging the monthly anomalies. The data density is illustrated in Figure 2 (top) for November-December 1987 , a poorly sampled bimonthly period at the beginning of the series, and for November-December 1991 (Figure 2, bottom), a typical bimonthly period following the mid-1988 increase in drifter launches. While the data coverage is insufficient at first, it becomes more adequate by NovemberDecember 1988, even though there are still a few periods where large gaps remain, as in the central equatorial Pacific during part of 1993.

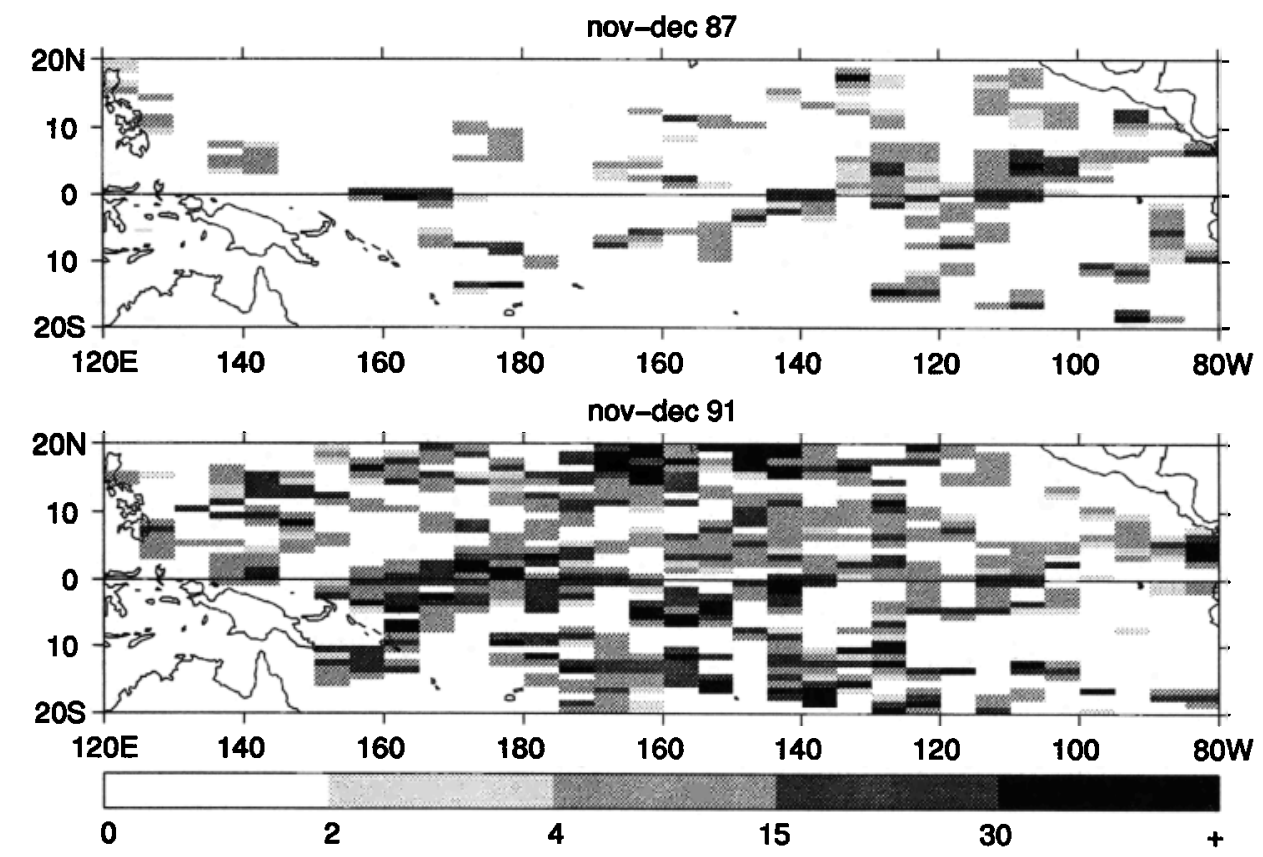

Figure 2. Number of zonal current days data for November-December (top) 1987 and (bottom) 1991. The moored currents have been distributed in equal number among the four boxes next to the mooring sites. 


\section{Objective Analysis}

The gridded anomaly data are noisy and distributed irregularly. The accuracy of the anomaly fields depends both on the density of measurement and the level of short-timescale oceanic variability. To map the velocity anomalies onto a uniform grid, we use an optimal interpolation technique [Bretherton et al., 1976], treating each velocity component and bimonthly period separately.

The objective analysis requires knowledge of the scales over which the data are correlated and, possibly, how this correlation varies in space and time. It also requires knowing the variance of the (true) signal, as well as having an estimate of the data noise and its space-time correlation. Thus the lagged covariance of the (true) signal must be given and the error covariance matrix of the data noise specified.

As little information is available for the spatial structure of the surface current anomalies, we use the present data set to estimate the lagged covariance of the velocity components. The correlation between pairs of gridded anomalies in individual bimonthly periods was found to approximately decrease exponentially in the zonal and meridional directions, so we choose for the lagged covariance of each velocity component the form

$$
C(r)=V \exp (-r / \lambda),
$$

where $r$ is the spatial separation, $V$ is the signal variance, and $\lambda$ is an $e$-folding scale. The spatial structure of tropical data is often approximated by a Gaussian formula rather than an exponential decay [e.g., White et al., 1982; Meyers et al., 1991], but (1) gives a better representation in the present case, presumably because our analysis is based on gridded averages rather than raw measurements, which filter the short spacetime fluctuations. The zonal velocity in some bimonthly periods also showed evidence of additional basin scales. The latter were not introduced in the objective analysis scheme, as the data density is generally sufficient to correctly resolve the largest scales.

For simplicity, we assume that the fields are spatially homogeneous but anisotropic, thus neglecting any regional and seasonal variability in the parameters, such as the large increase in zonal velocity variance as one approaches the equator. When estimated from the raw gridded bimonthly anomalies, the latter corresponds to a factor of 8 between $10^{\circ}$ and $0^{\circ}$, but this includes the equatorward increase in variance of both the high frequencies (see Figure A1 of REV) and the resolved basinscale motions (e.g., Figure 9). Thus the modulation of $V$ that would be needed in (1) should be much smaller, and indeed, the constant $V$ does not prevent the variance of the analyzed fields to increase equatorward as much as the raw data. The anisotropy is taken into account by stretching the meridional coordinate by a factor of 5 and treating the stretched data as isotropic, which is simpler than specifying a zonal and a meridional correlation scale. This anisotropy corresponds to that of the bin size $\left(5^{\circ} \times 1^{\circ}\right)$ and is equal to the ratio of zonal to meridional decorrelation scales found for the depth of the $20^{\circ} \mathrm{C}$ isotherm in the tropical Pacific by Meyers et al. [1991]. It was found to fit well the observations, as seen in Figure 3, where zonally and meridionally separated data points have been combined to estimate an averaged sample structure function for each velocity component, using 14 well-sampled bimonthly periods. Note that instead of using (1), we worked with the corresponding structure function, $V[1-\exp (-r / \lambda)]$. To

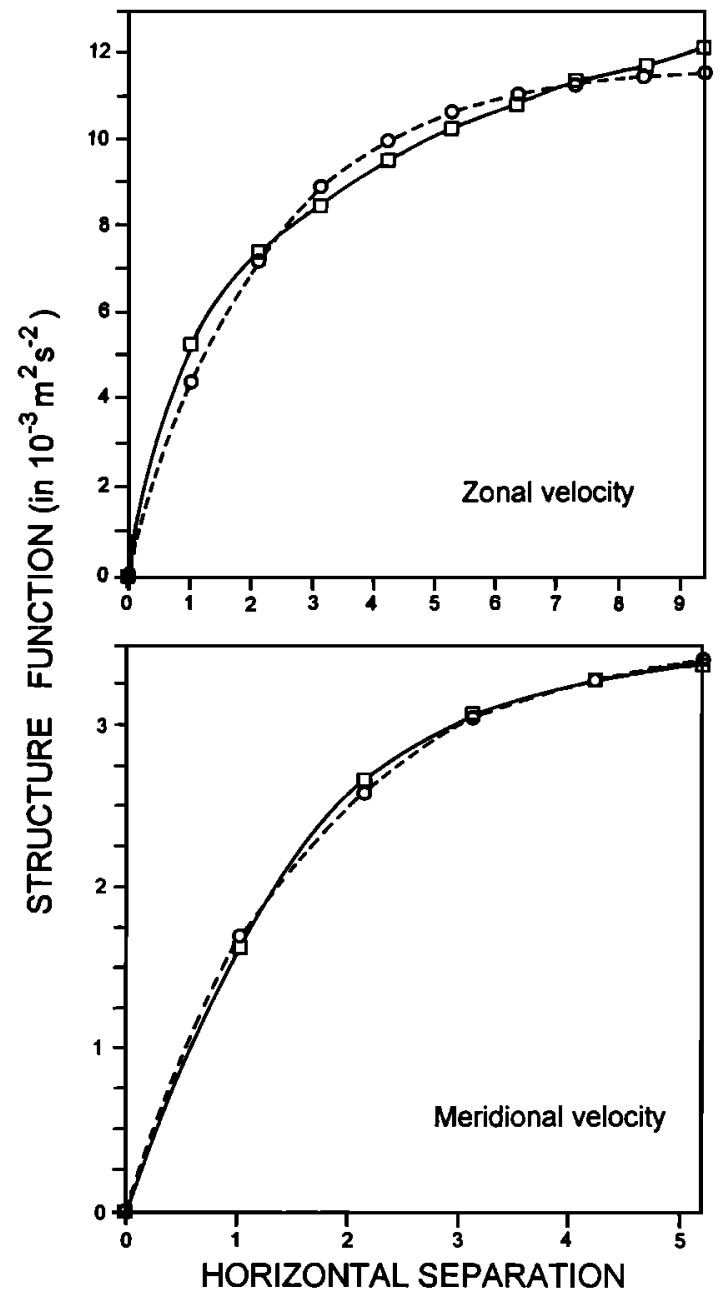

Figure 3. Structure function for (top) $u$ and (bottom) $v$ estimated from all the bimonthly periods available from January-February 1990 to March-April 1992 (drifter data only, squares) and analytical fit (circles) derived from expression (1).

construct the data points in Figure 3, we first estimated for each bimonthly period a sample structure function

$$
F\left(r_{l}\right)=\sum_{J}^{n t}\left(v_{\jmath}-\bar{v}\right)\left(v_{k}-\bar{v}\right) / n_{l}
$$

where an overbar indicates spatial averaging and $F(0)=0$, using all $n$, pairs of data (denoted by $j$ and $k$ ) separated by distances smaller than 10 spatial units $\left(5^{\circ}\right.$ in longitude and $1^{\circ}$ in latitude) for $u$ and 6 for $v$. As the locations of the current meters are not random within the $1^{\circ} \times 5^{\circ}$ bins, only drifter data were considered. Relation (2) is affected both by the lowfrequency variations and the high-frequency data noise. To coarsely estimate the latter, we calculated the variance of the bimonthly velocity anomalies at each grid point by using the variance of the monthly means, assuming for simplicity that data in 2 consecutive months are independent and neglecting the small effect of subtracting the climatological cycle from the monthly data. The high-frequency noise was also assumed to be spatially uncorrelated. An averaged noise over all the grid points entering the sum was then subtracted from (2), which is equivalent to removing uncorrelated noise from a covariance 

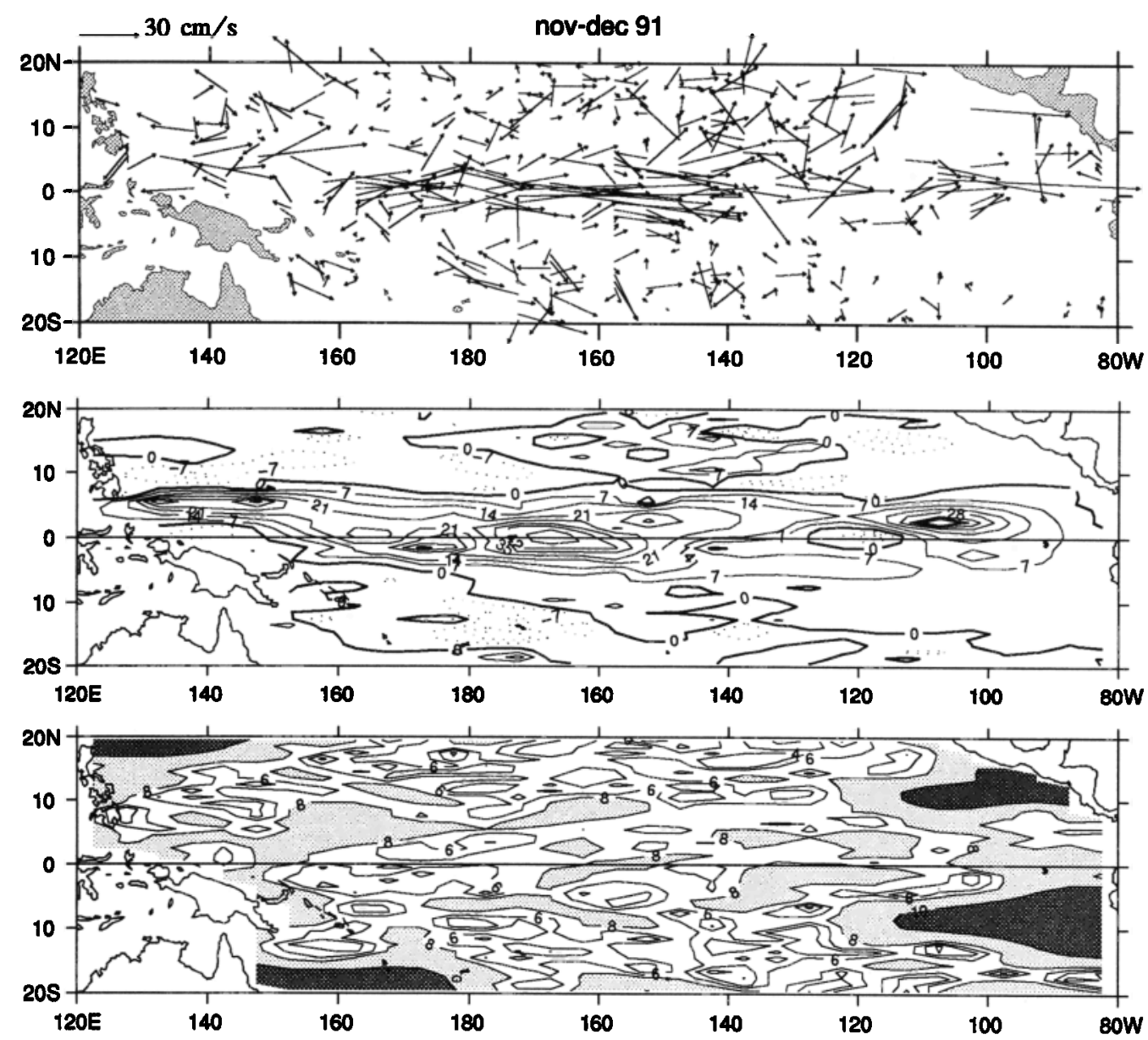

Figure 4a. (top) Raw current vector for November-December 1991 (scale at left). (middle) Analyzed zonal velocity (in centimeters per second). (bottom) Corresponding standard errors, with contour interval of $2 \mathrm{~cm}$ $\mathrm{s}^{-1}$ for $u$ and $1 \mathrm{~cm} \mathrm{~s}^{-1}$ for $v$; larger values are shaded.

function. The corrected sample structure functions for the 14 bimonthly periods were then averaged, using a weight proportional to the data density.

The adjustable parameters in (1) are the variance $V$ and the decorrelation scale $\lambda$, which were estimated by least squares fitting to the mean structure functions. The fit was very good for both velocity components, except for a small systematic offset, suggesting that the high-frequency noise had been slightly overestimated. The disparity disappeared when only $90 \%$ of the estimated noise variance was subtracted from the sample structure functions, so this is the case represented in Figure 3. A $10 \%$ reduction is well within the accuracy expected from the crudeness of our assumptions in estimating the number of independent samples at each grid point, whence it was also adopted for the analysis below. Note that the fit was also performed on individual bimonthly periods, showing, in most cases, a reasonable agreement with the model (1) but some variability in the estimated variance.

The fit yields decorrelation scales of 2.2 and 1.6 stretched units for $u$ and $v$, respectively. This corresponds to $e$-folding scales of $11.1^{\circ}$ longitude and $2.2^{\circ}$ latitude for $u$ and $8^{\circ}$ longitude and $1.6^{\circ}$ latitude for $v$, somewhat smaller than those found by Meyers et al. [1991] for the $20^{\circ} \mathrm{C}$ isotherm depth $\left(15^{\circ}\right.$ longitude and $3^{\circ}$ latitude). The signal variance $V$ in (1) is $1.210^{-2} \mathrm{~m}^{2} \mathrm{~s}^{-2}$ for $u$ and $3.410^{-3} \mathrm{~m}^{2} \mathrm{~s}^{-2}$ for $v$, so the rms value of the low-frequency, medium-scale anomaly currents given by the analysis is assumed to be 11 and $6 \mathrm{~cm} \mathrm{~s}^{-1}$ for $u$ and $v$, respectively. As pointed out before, the largest scales are not included in $V$ but are explicitly resolved, except when there are large data gaps. Note that the value of $V$ has very little impact on the analyzed fields but a strong influence on the error fields, as it completely determines the error in regions with no data coverage. Hence the more realistic use of a spatially varying variance $V$ would have primarily affected the errors but not the anomaly fields.

The anomalies in each velocity component were mapped for each bimonthly period, using zero as a first guess and limiting, for simplicity, the radius of influence to five correlation scales. The noise at each grid point was given by the (corrected) high-frequency noise, except when the bimonthly mean was derived from less than seven daily values for $u$ and five for $v$. Then, it was compared with the averaged variance over longitude and seasons at that latitude, divided by the effective number of samples. If the latter was larger than the noise, it was used instead. This avoids giving too much weight to data accidentally having too little dispersion, but may increase the smoothing. The full error covariance matrix of the analyzed fields was also estimated.

The analysis is illustrated in Figures $4 \mathrm{a}$ and $4 \mathrm{~b}$. The raw bimonthly anomaly currents are represented at all grid points where both components could be estimated (Figure 4a, top), but their accuracy is variable, as it depends on the data density, 

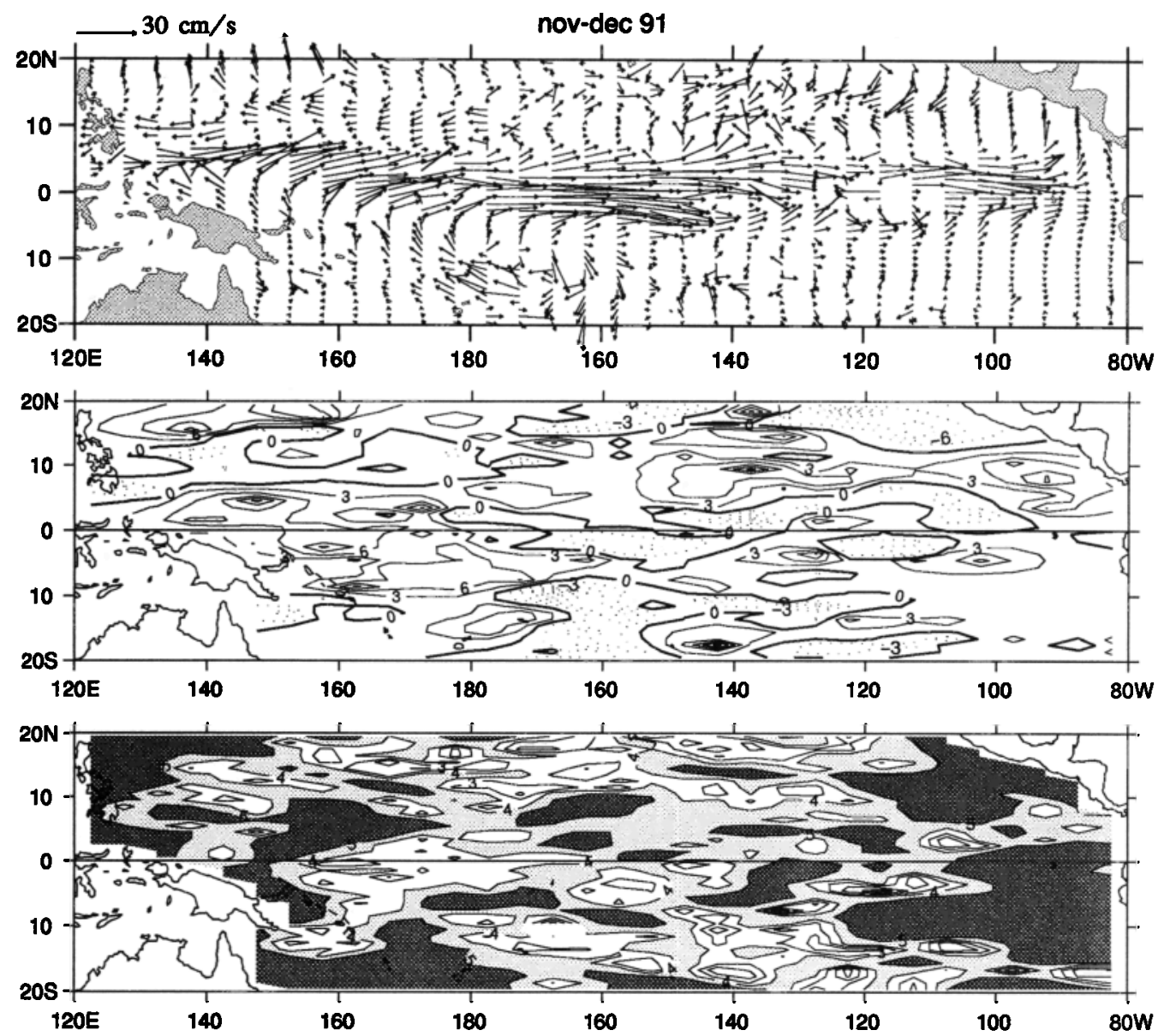

Figure 4h. (top) Analyzed vector map corresponding to Figure 4a, top (scale at left). (middle) Analyzed meridional velocity (in centimeters per second). (bottom) Corresponding standard errors, with contour interval of $2 \mathrm{~cm} \mathrm{~s}^{-1}$ for $u$ and $1 \mathrm{~cm} \mathrm{~s}^{-1}$ for $v$; larger values are shaded.

given in Figure 2 (bottom). Although the raw data are noisy, well-defined, large-scale structures can be seen and emerge from the analysis, given both in vector form (Figure $4 \mathrm{~b}$, top) and for each component (Figures $4 a$ and $4 b$, middle). The (univariate) standard error of the analyzed fields are given in Figures $4 \mathrm{a}$ and $4 \mathrm{~b}$ (bottom). The zonal component is rather well resolved and dominated by large-scale features, in particular, between about $10^{\circ} \mathrm{N}$ and $10^{\circ} \mathrm{S}$. The meridional velocity is more noisy and dominated by smaller scales, although peak values clearly stand above the noise. Note that the estimated noise in Figures $4 \mathrm{a}$ and $4 \mathrm{~b}$ only pertains to the "medium-scale" current anomalies represented by (1) and not to the largerscale ones. The error is thus underestimated if there are regions with large data gaps, as the radius of influence is limited to five correlation scales and current anomalies are set to zero in the absence of data. Because of the constant (hence averaged) value of the variance $V$ in (1), the errors are also likely to be underestimated in energetic regions, as near the equator, and overestimated elsewhere.

To decrease the noise in the analyzed maps and emphasize low-frequency variability, an additional 1-2-1 binomial filter was applied in the time domain. This slight smoothing yields an effective time resolution of about 4 months, slightly larger than that of the climatology (REV).

\section{The Velocity Anomalies}

\subsection{Observations}

The current anomalies are primarily zonal and the largest amplitudes are encountered within $8^{\circ}$ or so from the equator, often peaking in the vicinity of the date line where the wind stress variability tends to be largest. The anomalies generally have a larger amplitude than the mean seasonal currents (given in REV) west of the date line, but somewhat smaller east of it.

In Figure 5 (left) a longitude-time plot of the zonal current anomalies along the equator shows their temporal evolution in relation to corresponding bimonthly SST anomalies derived from the data of Reynolds and Smith [1994] (Figure 5, right). Note that the January 1987 to April 1992 period is a little warmer than the long-term climatology. Figure 5 shows that the zonal and temporal scales of the zonal current anomalies are large, but they are smaller than those of the SST anomalies, with a dominant scale of about a year.

The SST warming of the 1986-1987 El Niño started at the end of boreal summer 1986, and the SST anomaly peak was reached in most of the equatorial Pacific during summer 1987. The SST anomalies then decreased rapidly, reaching nearnormal conditions at the end of the winter. During this period 


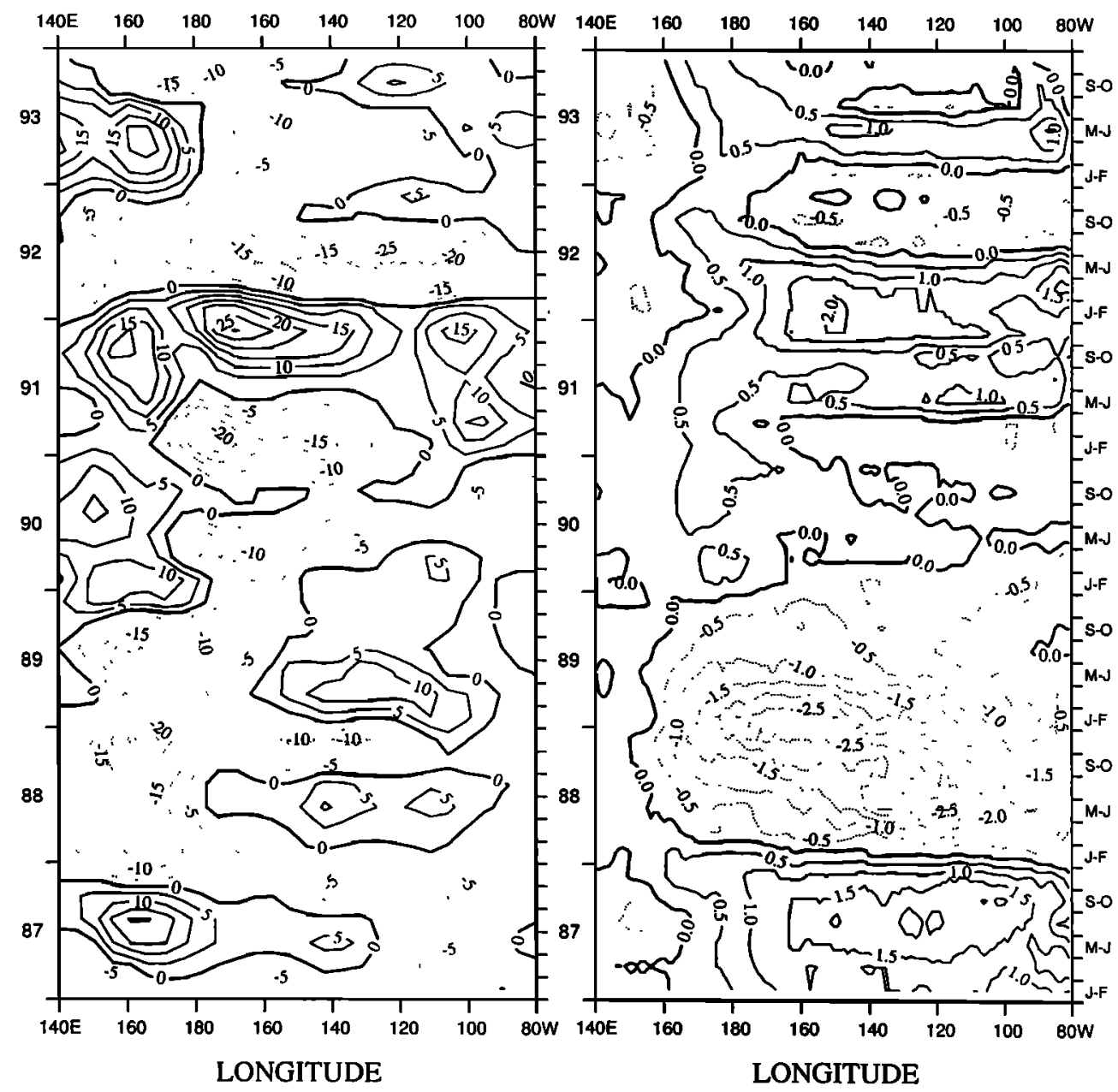

Figure 5. Time-longitude plot along the equator of (left) zonal current (in centimeters per second) and (right) sea surface temperature (SST) (in kelvins) bimonthly anomalies (averaged between $2^{\circ} \mathrm{N}$ and $2^{\circ} \mathrm{S}$ ) with respect to the January 1987 to April 1992 period. The SST observations are from Reynolds and Smith [1994].

the anomaly currents are rather small and mostly westward, except for a large anomalous eastward advection west of about $170^{\circ} \mathrm{W}$ from March-April to September-October 1987, which corresponds to the warmest SST, found between $160^{\circ} \mathrm{W}$ and $180^{\circ}$ W. Picaut and Delcroix [1995] have shown that these western currents can be interpreted in terms of locally and remotely forced Kelvin and Rossby modes, but here, neither the time resolution nor the sampling is sufficient for such an analysis. One should be cautioned that, as the anomaly currents are set to zero if there are no data and the sampling is poor until fall 1988, their smallness at the beginning of the series in Figure 5 may be, in part, an artifact of the analysis procedure, except at the mooring sites, at least after May 1988, when they are all occupied. The analyzed bimonthly maps (not shown) indicate that the anomalous eastward currents were centered around the equator, whereas the anomalous westward currents that prevailed east of $170^{\circ} \mathrm{W}$ were centered near $5^{\circ} \mathrm{N}$. The net surface flow at $165^{\circ} \mathrm{E}$ in July-August 1987 was eastward between about $3^{\circ} \mathrm{S}$ and $7^{\circ} \mathrm{N}$, in agreement with the zonal currents derived by McPhaden and Picaut [1990] from a single meridional section of shipboard velocity measurements, not included in our analysis.

Cold SST anomalies developed rapidly in the east during spring 1988, and a first peak was reached in May-June around $120^{\circ} \mathrm{W}$. The anomalous cooling extended westward and reached its maximum in November-December when SST anomalies over $-2^{\circ} \mathrm{C}$ were seen from $180^{\circ} \mathrm{W}$ to $100^{\circ} \mathrm{W}$, while to the east the anomalous temperature started to weaken. In the western Pacific, strengthening westward anomaly currents centered along the equator were encountered throughout 1988, showing a sustained anomalous westward advection until early 1989. On the other hand, in the central and eastern Pacific the equatorial current anomalies were small and variable during the first part of the year. Note that strong current fluctuations were present at higher frequencies [Picaut and Delcroix, 1995] but were filtered out by our analysis scheme. Nonetheless, the low-frequency currents are in reasonable agreement with the June 1988 section of McPhaden and Picaut [1990], possibly, in part, because drifters were launched during that cruise. During the second part of the 1988 the anomaly currents east of the date line became westward and by September-October, one bimonthly period before the peak of the 1988 La Niña, strong and broad westward anomalous currents covered most of the equatorial band. The 1988 evolution is briefly illustrated in Figure 6 . Note that when the sampling is poor and there is no basin-wide structure, the scales of the anomaly currents are partly given by the analysis procedure, whereas the latter have less influence when the data density is larger. 


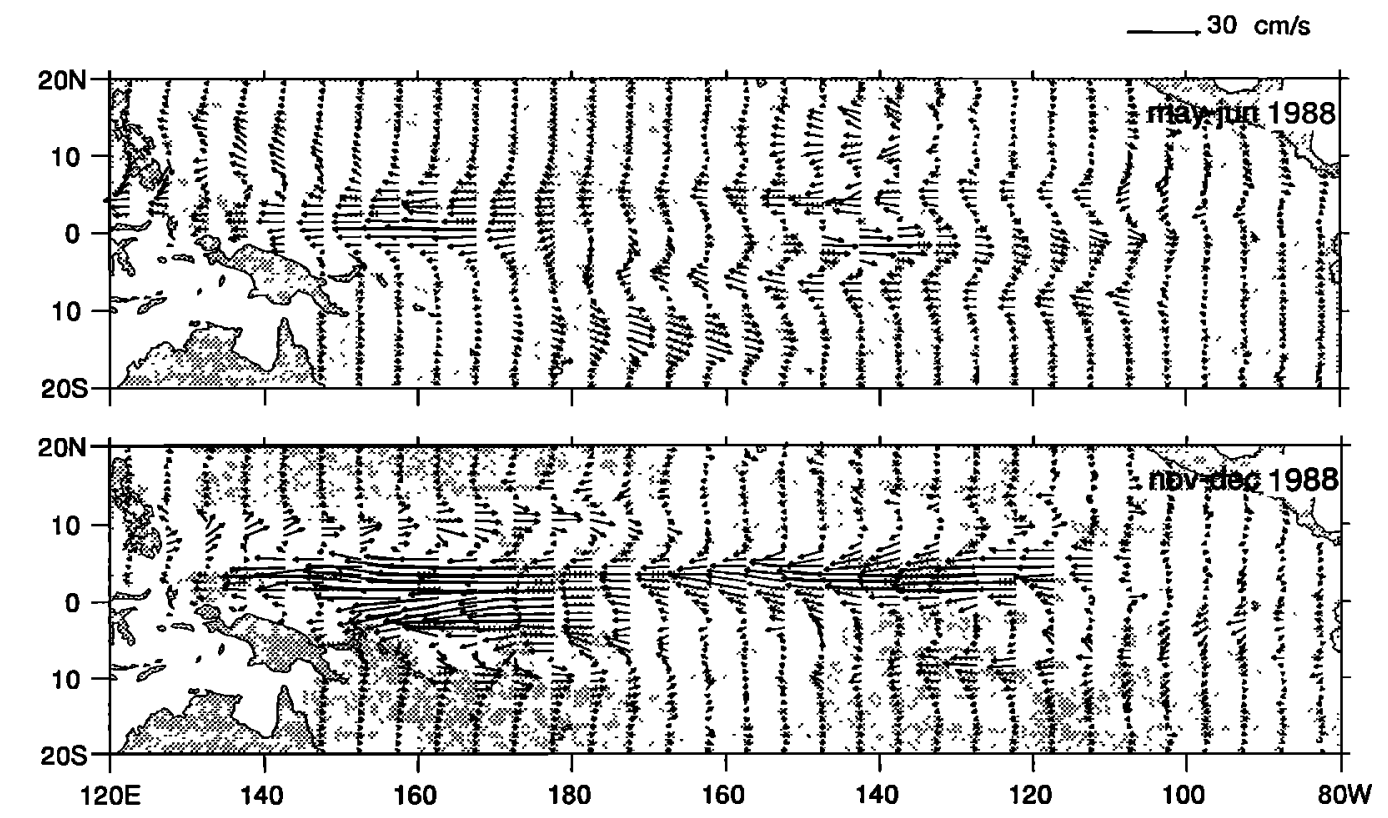

Figure 6. Anomaly currents (in centimeters per second) (top) May-June 1988 and (bottom) NovemberDecember 1988. The shaded regions mark grid points with no zonal current data in any of the three bimonthly periods used to construct each of the smoothed maps (section 3 ).

In spring 1989 the SST anomaly started increasing, and by summer the SST reached near-normal conditions, except in the central Pacific where the temperature remained somewhat below normal until the end of the year. Normal SST conditions persisted until spring 1991, when warm SST anomalies started to develop. In January-February 1989 the surface currents in the eastern and central equatorial Pacific started reversing and turned eastward, but they weakened after May-June and no strong anomalous current could be seen until NovemberDecember 1990, when westward anomalous currents appeared in the central Pacific, extending to the western Pacific by the beginning of 1991 and persisting until March-April 1991. Meanwhile, strong anomalous eastward equatorial currents developed in the eastern Pacific at the beginning of 1991. The anomalous currents during this "normal" period were somewhat stronger in the western Pacific, where a strong westward jet was seen near the equator in summer 1989, followed by persistent but moderate eastward current anomalies which lasted until the end of 1990 (Figure 7).

In May-June 1991, significant positive SST anomalies appeared along the equator, but the 1991-1992 El Niño warming only developed in September-October 1991, reaching a peak in the central Pacific in January-February 1992 and at the eastern coast in March-April 1992. In May-June 1991 the surface current anomalies started reversing and becoming eastward in the east and in the west, and by June-August, broad and strong eastward anomaly currents were observed across the entire equatorial Pacific (Figure 7). The large anomalous eastward advection persisted for 8 months, peaking in November-December 1991 and strongly contributing to the eastward extension of the Pacific warm pool. It is shown in section 5 that zonal advection does not contribute significantly to the SST changes east of about $120^{\circ} \mathrm{W}$, so the SST rise in the east was presumably due to upwelling changes.

In March-April 1992 the SST anomaly began to decrease in the central Pacific, and at the same time, a current reversal was seen in the eastern and western Pacific, while anomalous east- ward currents were persisting in the central Pacific, south of the equator. By May-June 1992 the warm event was over and strong basin-wide westward equatorial currents were established (Figure 7), weakening in September-October.

The warm event was not followed by a cold one, and the temperatures remained close to normal (with respect to the present climatology) until the end of 1993. During 1993 (no map shown) the currents until July-August were strongly eastward west of the date line and weak and variable elsewhere, while at the end of the analysis period, broad but weak eastward and westward anomaly currents seemed to converge in the western equatorial Pacific near $160^{\circ} \mathrm{E}$ (Figure 5), with little activity elsewhere.

\subsection{Patterns of Variability}

To document the main patterns of variability of the anomaly currents, we performed a principal component analysis for each velocity component. The analysis is limited to a smaller, concave domain which is reasonably well sampled, except in two areas near the equator, where the analyzed signal is likely to have been underestimated (Figure 8). Note that the largest data density is at the location of the four equatorial moorings, which stresses their crucial role in complementing the drifters and monitoring the equatorial currents.

As expected, the zonal component is least noisy, and seven empirical orthogonal functions (EOFs) already account for more than $80 \%$ of the variance. The dominant EOFs and principal components correspond to low-frequency, basin-wide fluctuations related to ENSO. In the first EOF (33\% of the variance) the zonal anomaly currents have one sign across the whole equatorial band between about $8^{\circ} \mathrm{N}$ and $8^{\circ} \mathrm{S}$, with the largest values at the equator in the western Pacific, and slightly north of it in the central Pacific (Figure 9a, top). As the time series (principal component) is normalized, the amplitude of the EOF pattern is indicative of the zonal current (in centimeters per second) (Figure $9 \mathrm{~b}$, top). Also shown are the 95\% 
$30 \mathrm{~cm} / \mathrm{s}$
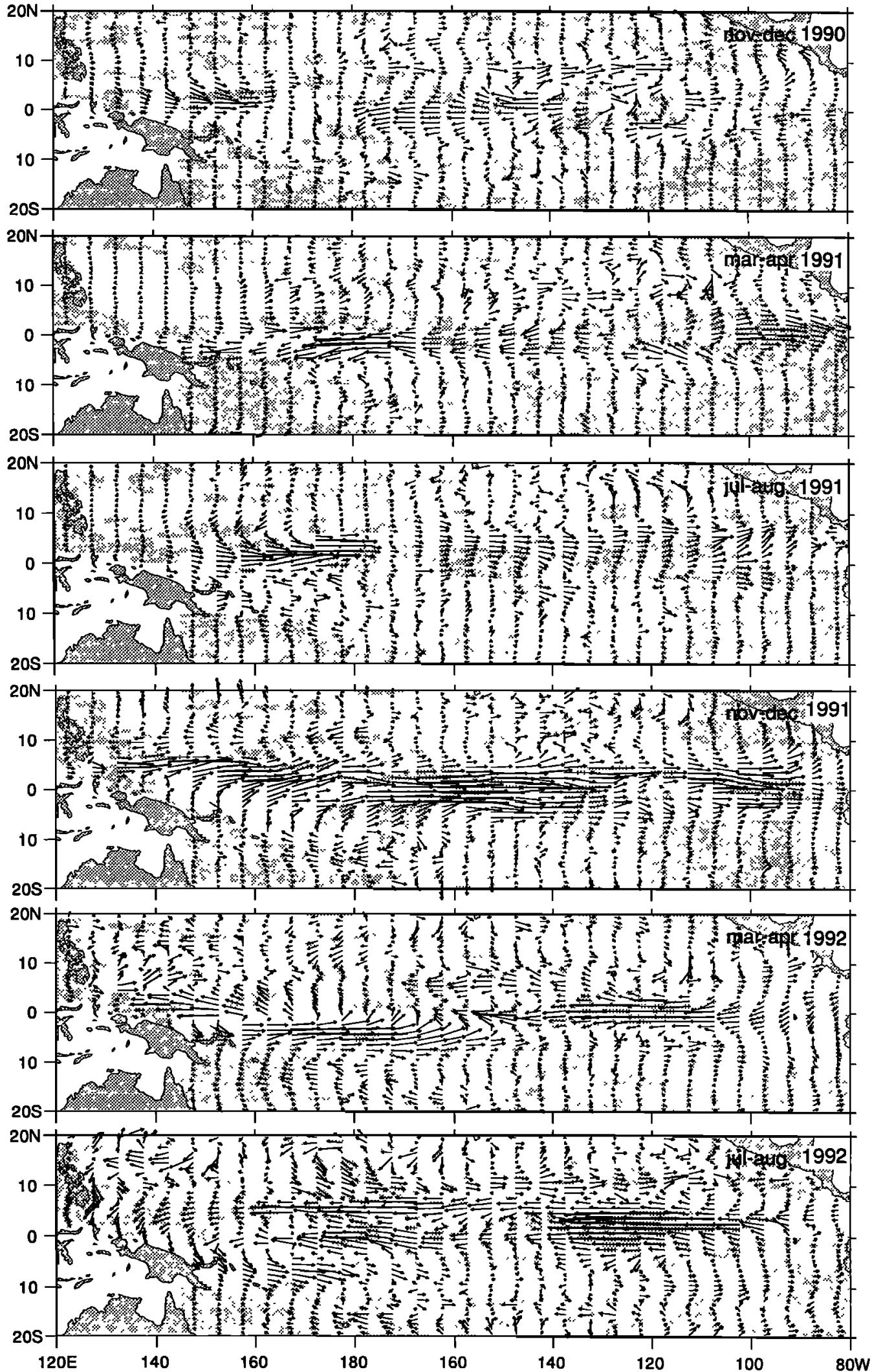

Figure 7. Anomaly currents (in centimeters per second) at bimonthly intervals from November-December 1990 to July-August 1992. The shaded regions mark grid points with no zonal current data in any of the three bimonthly periods used to construct each of the smoothed maps. 


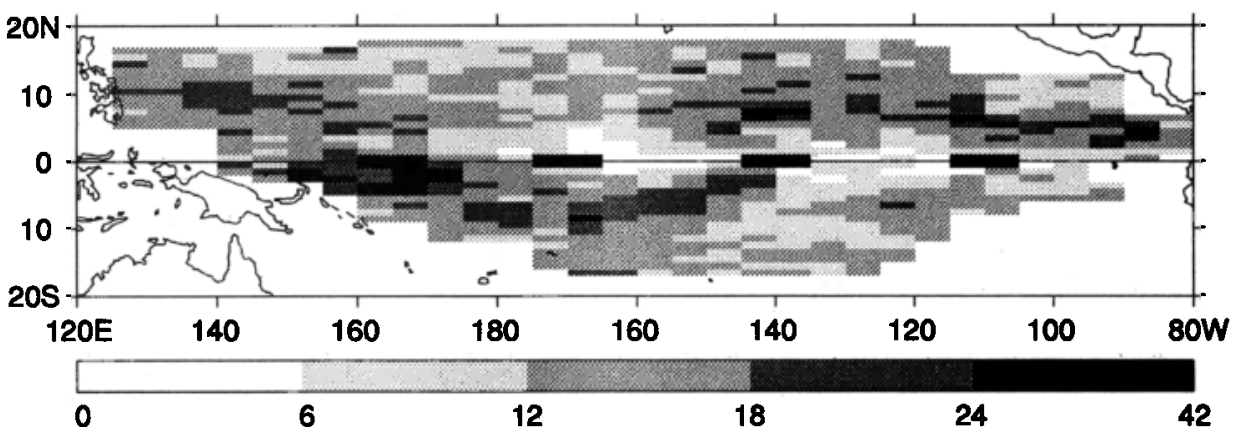

Figure 8. Limited domain for the empirical orthogonal function (EOF) analysis. The total number of bimonthly periods with zonal current data is indicated at bottom. The data density is a little larger for the meridional component.

confidence intervals, which are estimated by assuming normality and projecting the error covariance matrix of the analyzed bimonthly fields onto the EOF pattern; the confidence interval is then given by $\pm 1.96 s$, where $s$ is the squared root of the error variance. Note the larger noise reflecting the poor sampling at the beginning of the record and the large signal-tonoise ratio during the three active periods associated with the large ENSO fluctuations. The second EOF ( $16 \%$ of the variance) mainly describes zonal currents of opposing direction west and east of $175^{\circ} \mathrm{W}$ and peaking at the equator, while the third one (11\% of the variance) shows anomalous zonal currents which are primarily alternating in sign between the two hemispheres. The second and third eigenvalues are close and the patterns sensitive to rotation, however, so that slightly different patterns might be obtained in longer data sets. Although the signal-to-noise ratio decreases with increasing EOF number, it does so slowly and remains large for at least 10 EOFs, which suggests that our data set is adequate to describe the zonal current fluctuations.

On the other hand, the meridional velocity component is more noisy, and the first seven EOFs only represent $60 \%$ of the variance. The dominant scales are rather large, as illustrated in Figure 10 by the first EOF, which represents $14 \%$ of the variance, but is sensitive to details in the calculation. As the noise level (estimated by the $95 \%$ confidence intervals) of the principal component time series quickly becomes large for the higher EOFs, it appears that the drifter sampling was insufficient to capture adequately the meridional velocity fluctuations.
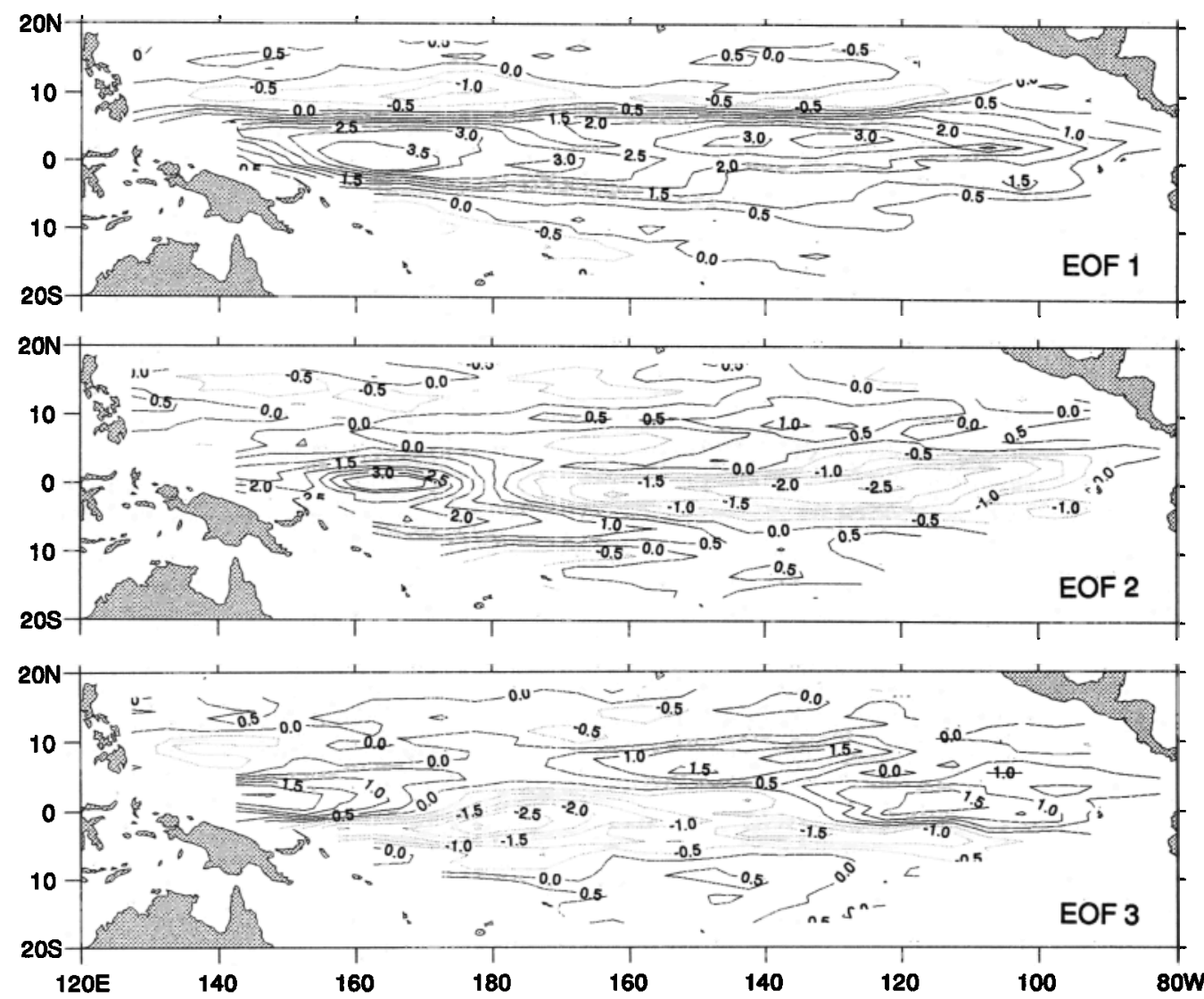

Figure 9a. First three EOFs of the zonal velocity anomalies, with contour interval in centimeters per second. 

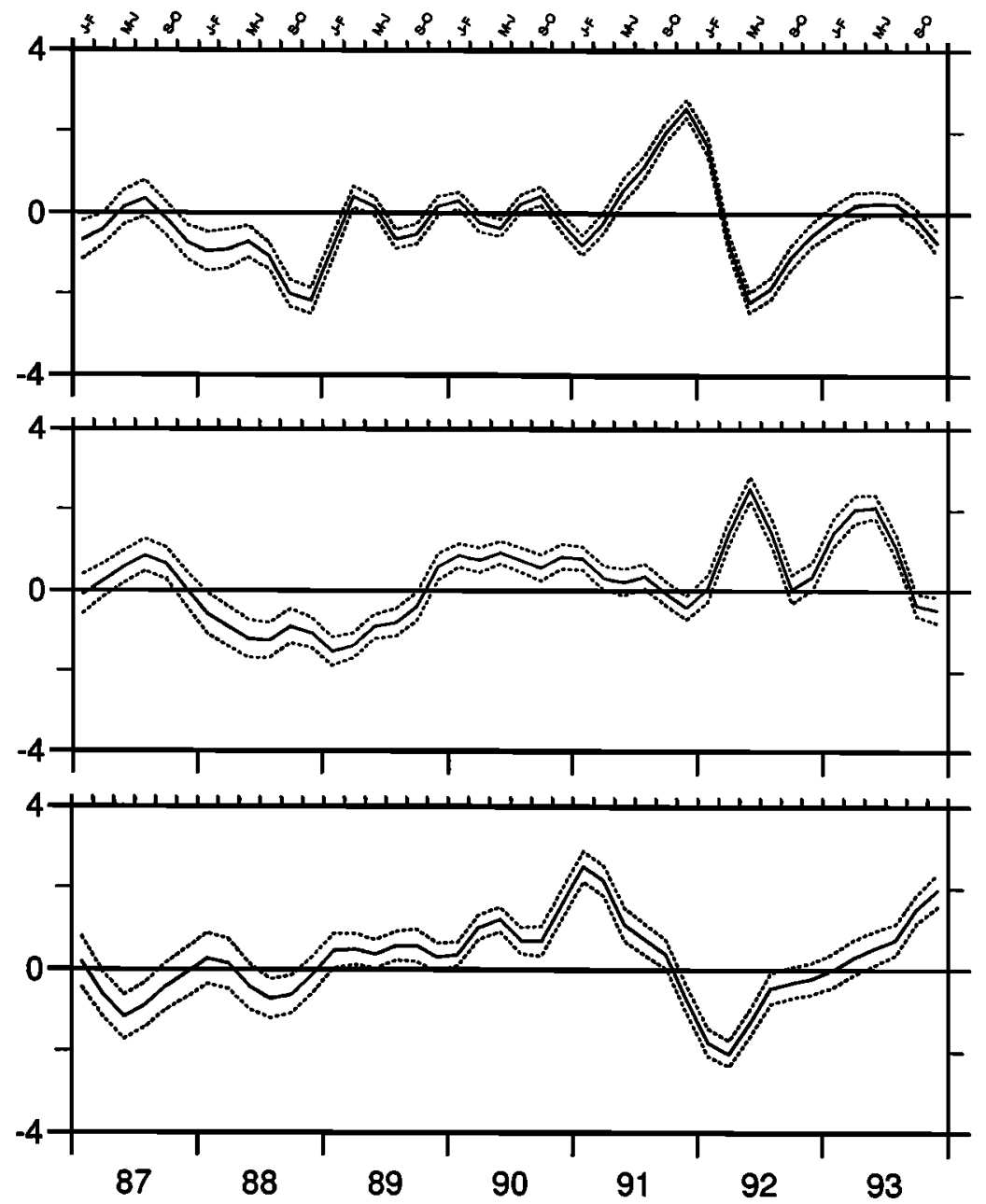

Figure 9b. Normalized principal component time series correspond to Figure 9a. The dashed lines indicate (univariate) $95 \%$ confidence intervals.

\section{Advection Effects on SST Anomalies}

The present data set and the mean seasonal currents of REV describe the large-scale, low-frequency surface currents during 1987-1993. In this section they are used to estimate their influence on the SST anomalies, although even an approximate balance between SST anomaly rate of change and anomalous advection is not expected, as there are other important terms in the SST anomaly equation which are not considered, like surface heat exchange, vertical advection, mixing, and SST advection by synoptic eddies and instability waves.

In addition to the present data set and the seasonal currents of REV, we use the high-resolution weekly SST product of Reynolds and Smith [1994], which combines in situ SST data and satellite SST retrievals, using optimum interpolation analysis. First, the SST is calculated on a $1^{\circ} \times 5^{\circ}$ grid of the surface currents. The SST advection by the net (seasonal plus anomalies) surface currents is calculated, using centered finite differences to estimate the derivatives, and the calculation is limited to the better-sampled domain in Figure 8. Bimonthly anomalies are then calculated with respect to the 1987-1993 seasonally varying climatology. To get more insight, the zonal and meridional advection anomalies are also decomposed into anomalous advection of mean SST, anomalous advection of anomalous SST (minus its mean, since we are only considering anomalies), and mean advection of anomalous SST, yielding the standard expression

$$
\begin{aligned}
\partial_{t} T^{\prime} & +u^{\prime} \partial_{x} \bar{T}+\bar{u} \partial_{x} T^{\prime}+v^{\prime} \partial_{y} \bar{T}+\bar{v} \partial_{y} T^{\prime} \\
& +u^{\prime} \partial_{x} T^{\prime}-\overline{u^{\prime} \partial_{x} T^{\prime}}+v^{\prime} \partial_{y} T^{\prime}-\overline{v^{\prime} \partial_{y} T^{\prime}}
\end{aligned}
$$

where $T$ is SST, a prime denotes a bimonthly anomaly, and an overbar denotes the seasonally varying climatology. In their study based on moored current meter data, Kessler and McPhaden [1995] have stressed that the calculation of the meridional advection term at the equator was very sensitive to the differencing scheme and that only upstream differencing could reflect the generally equatorward eddy heat flux associated with the tropical stability waves. However, our estimates were found to be insensitive to the differencing scheme, presumably because instability waves are not resolved in bimonthly data, and the equator is a boundary between grid boxes, so the differencing is not done symmetrically about the equator.

The correlation between the rate of change of the SST anomalies and (minus) the anomalous advection effects has been calculated at each grid point. The results were somewhat noisy, so the data have been averaged on a $2^{\circ} \times 10^{\circ}$ grid. The correlations are given in Figure 11 for zonal and meridional 

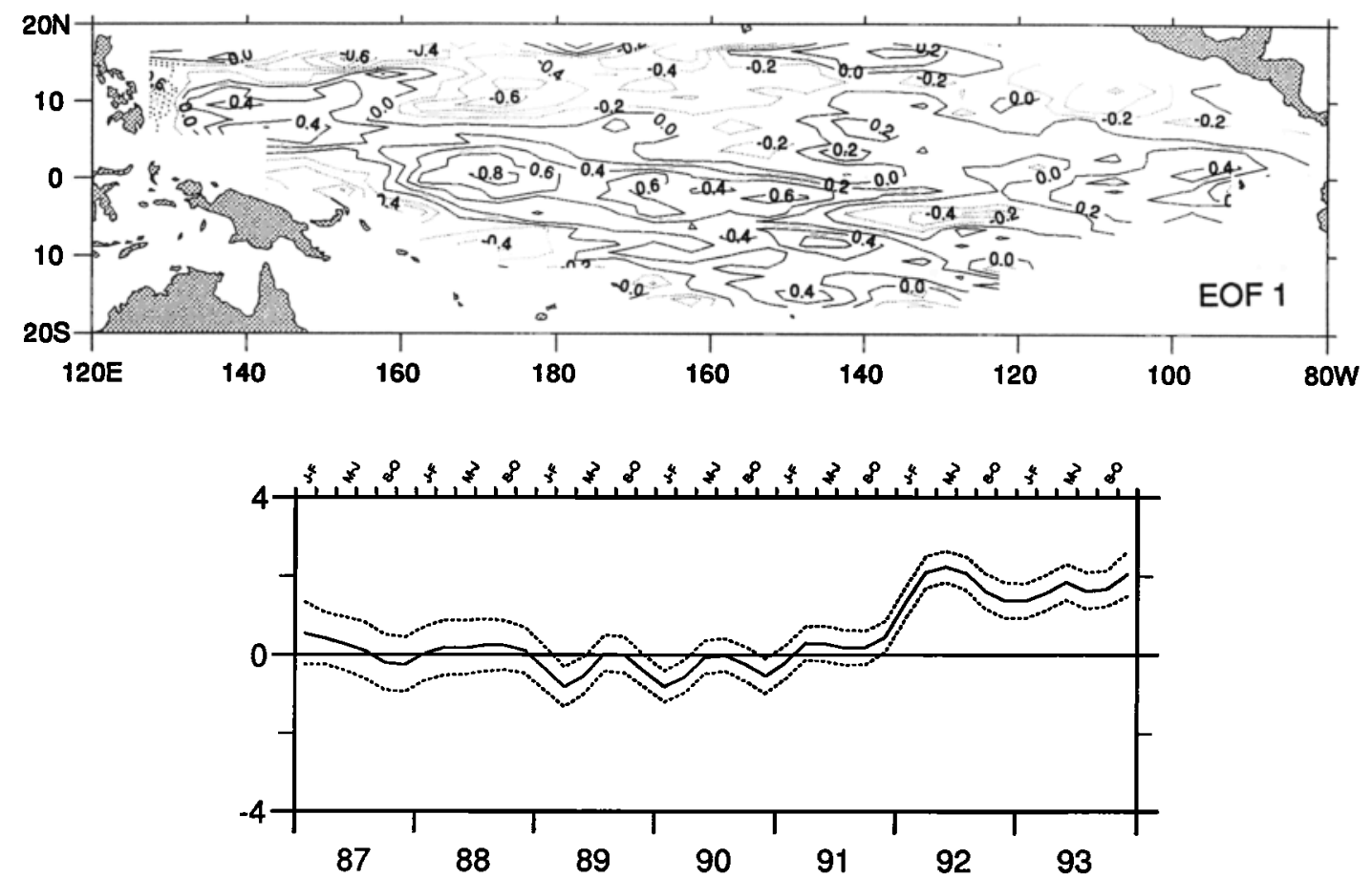

Figure 10. (top) First EOF of the meridional velocity anomalies, with contour interval in centimeters per second. (bottom) Corresponding normalized principal component time series. The dashed lines indicate (univariate) $95 \%$ confidence intervals.

advection. Their statistical significance is difficult to establish, since there is some serial correlation in most of the time series. If there were no serial correlation, there would be 42 (number of bimonthly periods) -12 (two mean seasonal cycles) $=30$ degrees of freedom, hence a correlation larger than 0.3 would be significant at the 5\% level (one-sided test). An equivalent number of degrees of freedom averages to about half, so, as an admittedly coarse approximation, we use 0.4 in Figure 11 to indicate grid points where the correlation is likely to be significant at the $5 \%$ level (dark shading). Correlations between 0.2 and 0.4 (medium shading) might still indicate advection effects, but their statistical significance is very low.
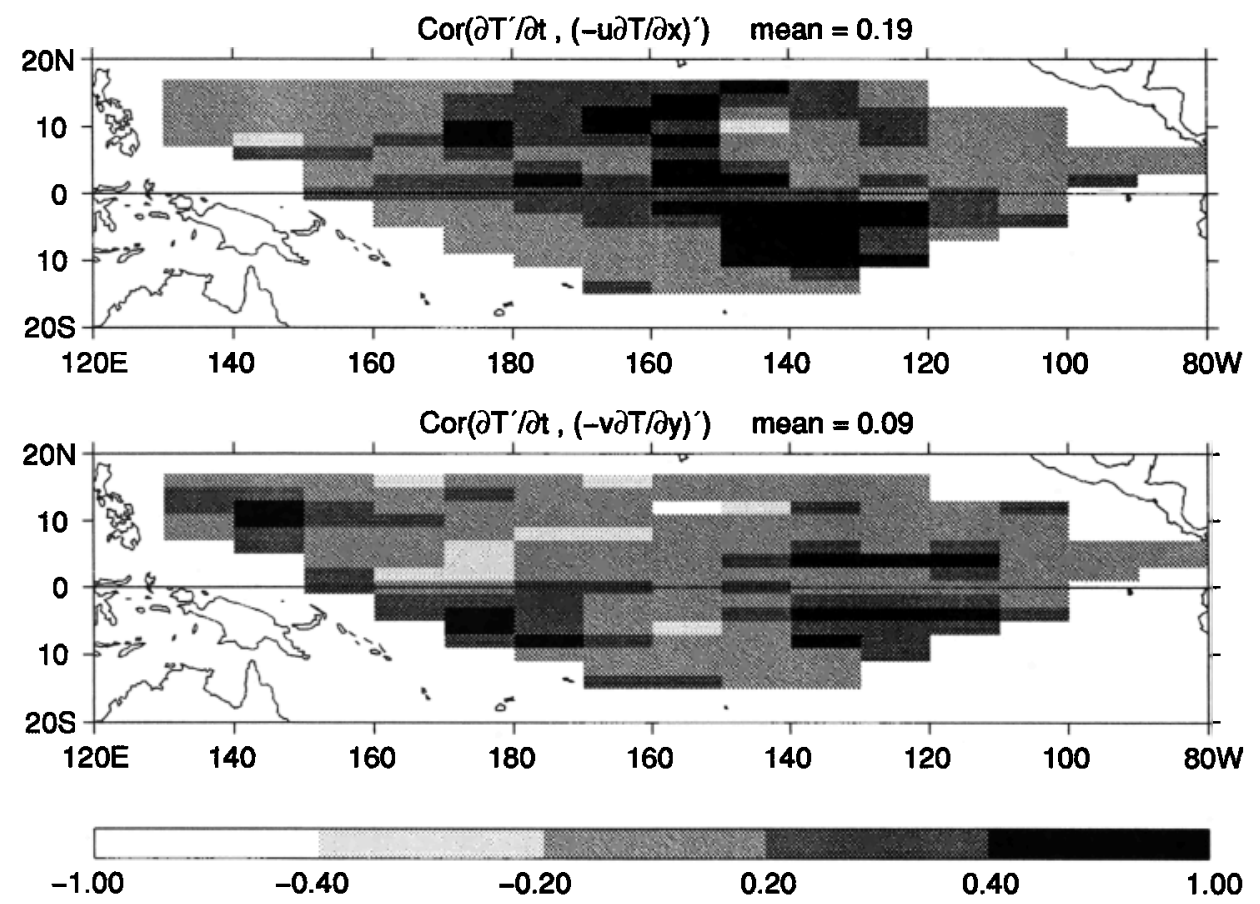

Figure 11. Correlation between anomalies in the rate of change of SST and minus (top) zonal and (bottom) meridional advection for the period 1987-1993. A coarse estimate of the 5\% significance level is 0.4 . 

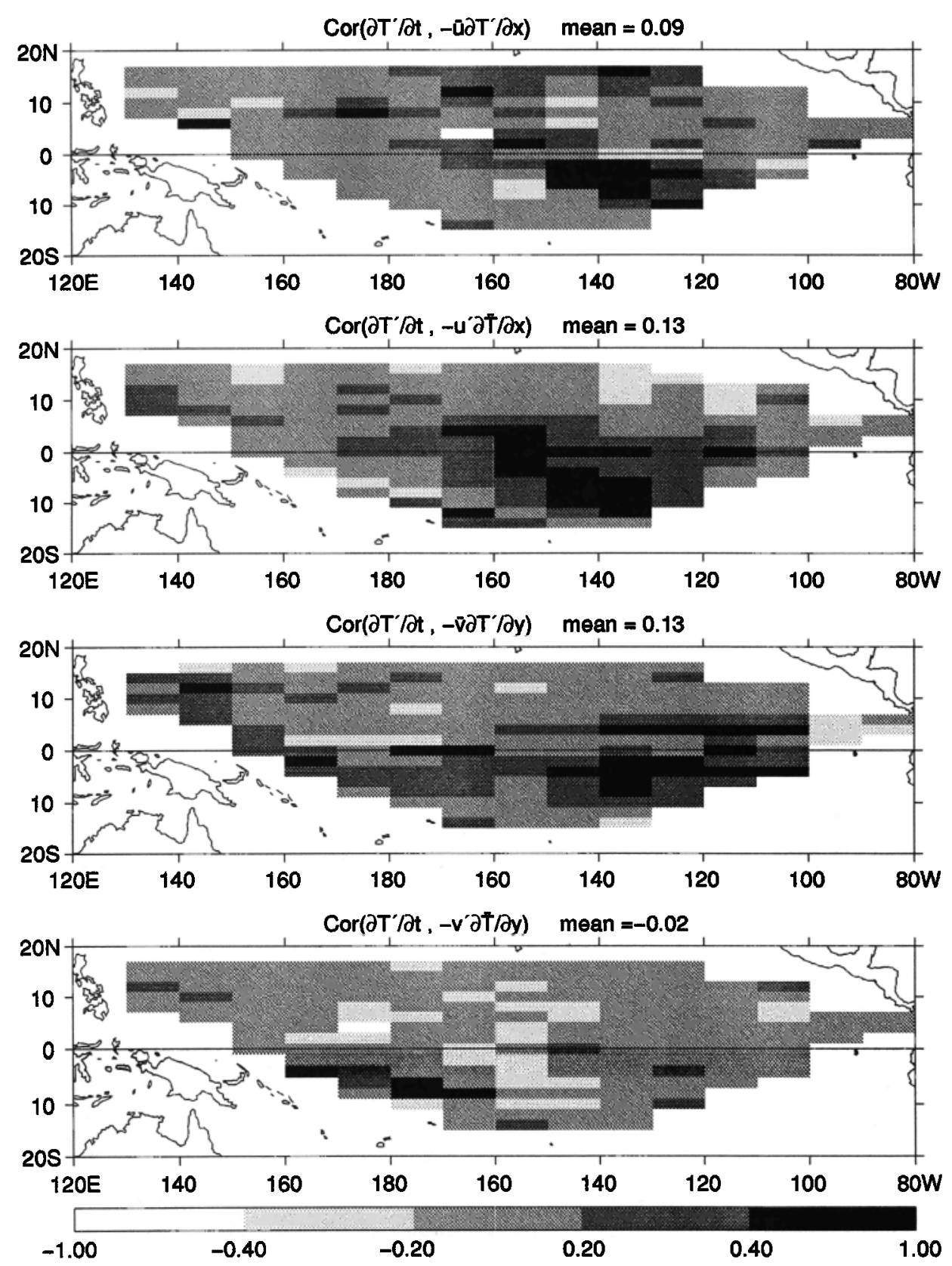

Figure 12. Same as in Figure 11, but (from top to bottom) for mean zonal advection of SST anomalies, anomalous zonal advection of mean SST, mean meridional advection of SST anomalies, and anomalous meridional advection of mean SST.

Zonal advection (Figure 11, top) is rather well correlated with the SST anomaly rate of change (for brevity, the fact that we are considering minus the advection terms will not be repeated); the correlations are positive over most of the domain (spatial average, 0.19 ), a large proportion (11\%) of "significant" correlations at the $5 \%$ level is found, and the results are stable to changes in the grid size or to limiting the calculation to the better-documented period starting in NovemberDecember 1988 (not shown). The correlations are largest in the central Pacific between $170^{\circ} \mathrm{E}$ and $100^{\circ} \mathrm{W}$, except near the equator east of $120^{\circ} \mathrm{W}$, where little correlation is found, possibly because of the dominance of equatorial upwelling in the SST changes. Note that the magnitude of the zonal advection term is smaller than that of the temperature rate of change, so that other effects must also play an important role. This is emphasized in the "maximum covariance analysis" below.

The correlations with meridional advection (Figure 11, bottom) are a little weaker, although the correlations are rather high between $150^{\circ} \mathrm{W}$ and $110^{\circ} \mathrm{W}$, except at the equatorial grid points, and in two areas of the western Pacific. Interestingly, the correlations in the former region become much smaller when the calculation starts in the November-December 1988 period, although the prior data coverage was much poorer. In particular, the drifter density in the eastern part of the basin was rather low in 1987 and poor during the first half of 1988. However, it is shown below that the large correlations in the eastern Pacific are mainly due to SST anomaly advection by the mean meridional currents during $1987-1988$, so they may 


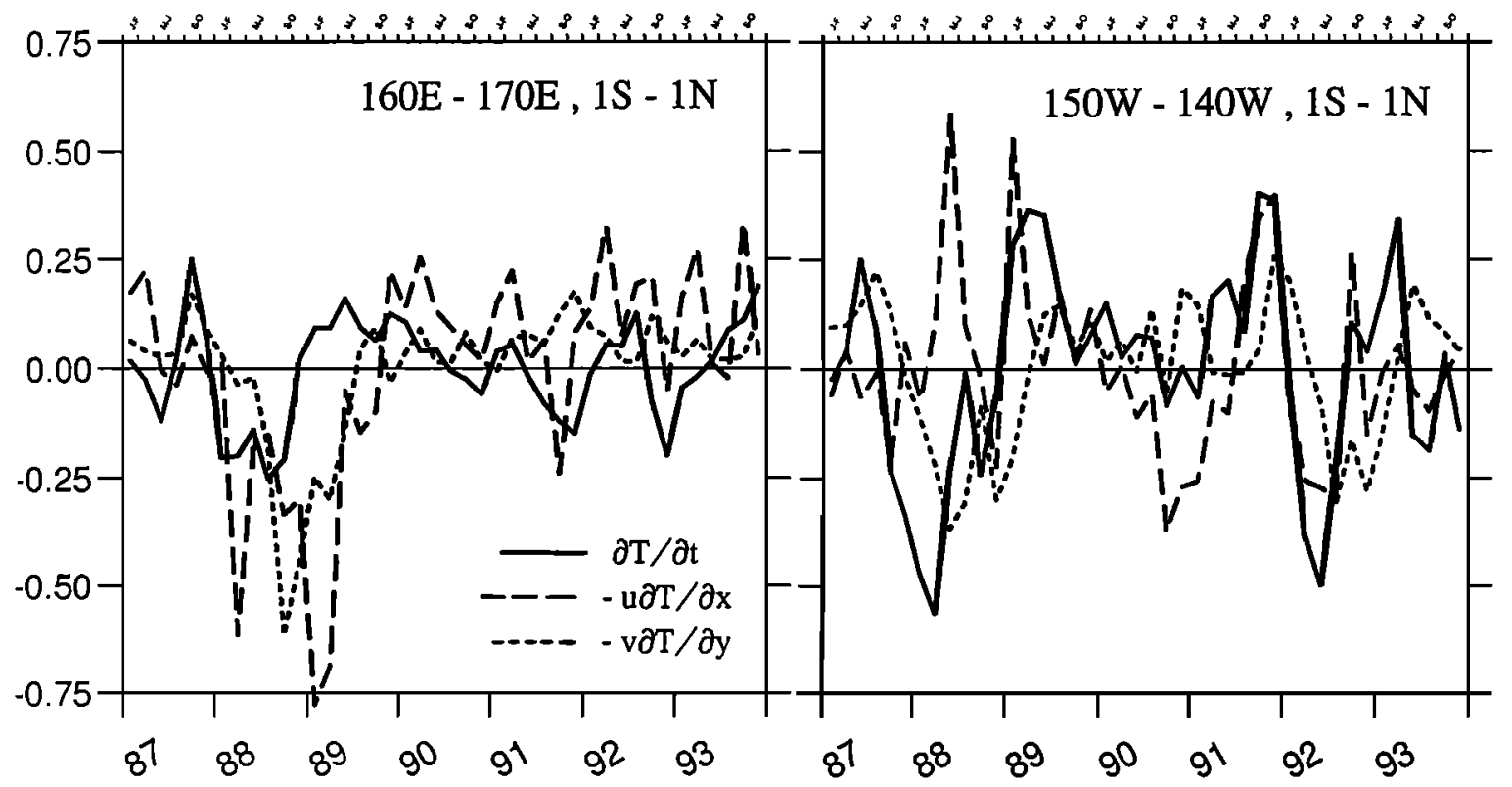

Figure 13. Interannual variations of bimonthly anomalies (in degrees Celsius per month) of SST rate of change (solid line) minus the zonal SST advection (long-dashed line) and minus the meridional SST advection (short-dashed line) in the (left) $160^{\circ}-170^{\circ} \mathrm{E}$ and (right) $150^{\circ} \mathrm{W}-140^{\circ} \mathrm{W}$ boxes.

not be too strongly affected by the poor sampling during this period.

The correlation was repeated separately for the anomalous advection of mean SST, the anomalous advection of anomalous SST, and the mean advection of anomalous SST. The results (Figure 12) show that the anomalous zonal advection of mean SST and the mean zonal advection of anomalous SST contribute about equally to the correlations in Figure 11, the former being dominant near the equator, in particular, after 1988. As noted above, the correlations with the meridional advection primarily come from the mean advection of anomalous SST during 1987-1988. Such effects are not unexpected in the central Pacific, since the mean meridional current at the equator is large during some seasons, and its yearly mean reaches about $10 \mathrm{~cm} \mathrm{~s}^{-1}$ slightly off the equator (see REV). A weak influence of the anomalous meridional advection is also detected at the equator between $100^{\circ} \mathrm{W}$ and $80^{\circ} \mathrm{W}$. Whether the smallness of the influence of the meridional current anomalies is physical or reflects the noise in their estimates is not known. In both cases the anomalous advection of anomalous SST has negligible effects (not shown).

Our analysis suggests smaller zonal advection effects than that of Picaut and Delcroix [1995], who used Geosat-derived currents and suggested that anomalous zonal advection dominated the SST changes along the eastern edge of the warm pool from December 1986 to August 1988. However, their time resolution is finer, the data coverage is better, and the calculation was done for a region that follows the eastern edge of the warm pool, starting from $165^{\circ} \mathrm{E}-180^{\circ} \mathrm{E}$ and going as far east as $150^{\circ} \mathrm{W}-130^{\circ} \mathrm{W}$ in mid- 1987 , hence it is not representative of the Eulerian viewpoint adopted here. For comparison, Figure 13 (left) shows the evolution of the anomalies in SST rate of change (solid line), zonal (dashed line), and meridional (dotted line) advection at the equator near $165^{\circ} \mathrm{E}$. Although the data are noisy, it is seen that the anomalous SST cooling during the $1988 \mathrm{La}$ Nina is indeed largely due to anomalous westward advection but that meridional advection also contributes sub- stantially. Note that while the SST anomaly starts increasing at the end of 1988, the advection of colder water persists until fall 1989 , so that other effects must have been dominant.

Figure 13 (right) illustrates the time series in the middle of the basin, where zonal advection seems particularly active, especially during the 1991-1992 El Niño, although meridional advection effects are also seen. Because of the strong vertical shear of the near-surface currents, Kessler and McPhaden [1995] found, using moored current meter data, that at $0^{\circ}$, $140^{\circ} \mathrm{W}$ the advective effects were smaller when integrated over an upper layer of $50 \mathrm{~m}$ thickness, and they ascribed the bulk of the 1991-1992 SST changes to upwelling variations. The present data set suggests larger advective effects but does not allow one to take the shear into account, hence it is only representative of advection effects at $15 \mathrm{~m}$ depth in regions of strongly sheared currents.

To emphasize the dominant large-scale patterns, a maximum covariance analysis based on a singular value decomposition (SVD) of the covariance matrix of the rate of change of SST anomalies and advection anomalies has also been performed. As discussed by Bretherton et al. [1992], SVD isolates the linear combinations of spatial variables within two fields that maximize the covariances between the two fields. The technique is less sensitive to small-scale noise than the pointby-point correlations, and it reflects covariances rather than correlations, thus providing a complementary view.

The dominant linear combination for the rate of change of SST and zonal advection anomalies yields two expansion coefficient, which are represented in Figure 14 (bottom). The combination explains $0.44\left({ }^{\circ} \mathrm{C} \text { month }^{-1}\right)^{2}$, which corresponds to $64 \%$ of the total squared covariance; the correlation between the two expansion coefficients is 0.73 . Figure 14 (top and middle) shows the corresponding "homogeneous covariance maps" which represent the (temporal) covariance of each expansion coefficient and the corresponding field. The patterns have a maximum amplitude in the equatorial waveguide and little amplitude elsewhere, contrary to the correlation maps. 

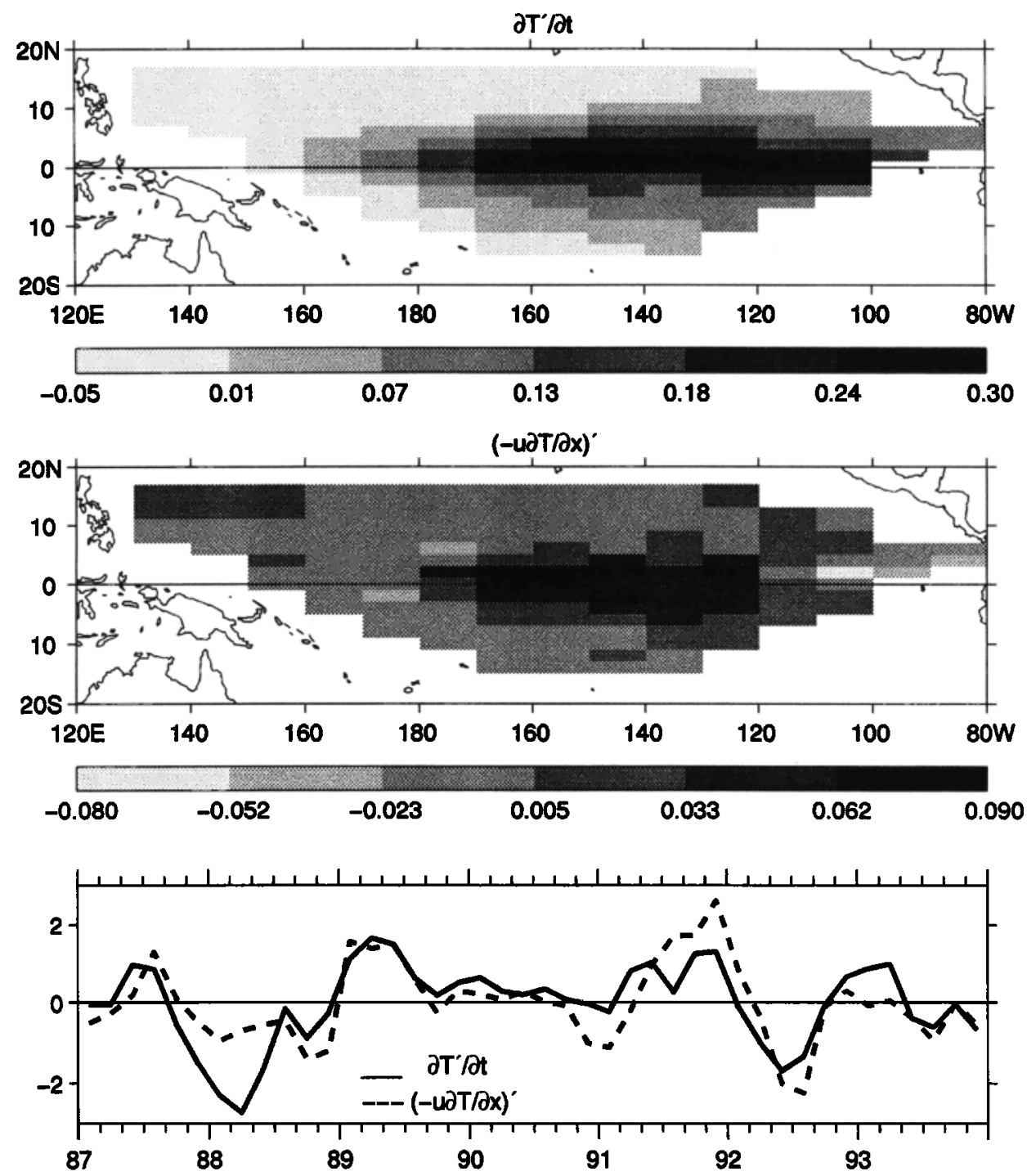

Figure 14. Singular value decomposition of zonal advection effects on SST anomalies. Homogeneous covariance maps for the dominant mode of (top) the rate of change of SST anomalies and (middle) minus the zonal advection anomalies. Units are in $\left({ }^{\circ} \mathrm{C} \text { month }{ }^{-1}\right)^{2}$, but note the two different scales. (bottom) Corresponding normalized time series in solid and dashed lines, respectively.

The dominant mode for the rate of change of SST anomaly has one sign across most of the equatorial Pacific, with a large amplitude in a large region located between about $180^{\circ} \mathrm{W}$ and the eastern coast. That for zonal advection is rather similar, but the amplitude is only large between $170^{\circ} \mathrm{W}$ and $120^{\circ} \mathrm{W}$, becoming even negative at the eastern coast (this latter feature is associated with the mean advection of anomalous SST). The agreement in patterns is particularly good when the SVD is made with the anomalous advection of mean SST, except for a shorter eastward extent of the advection effects (not shown). Noteworthy is that the amplitude of zonal advection is smaller than that of the rate of change of SST anomaly. This could occur if zonal advection was acting in phase with other important terms in the SST equation, like vertical entrainment or mixing, as expected if the (unresolved) equatorial Kelvin waves play a large role; indeed, zonal current and thermocline depth would then be in phase. This could also explain the differences in the eastward extensions of the patterns, as upwelling becomes increasingly dominant eastward. However, it should be recalled that the anomaly currents are likely to be underestimated in two poorly sampled equatorial areas. The time series show that zonal advection played a role in the 1988 La Niña (mostly the mean advection of anomalous SST) and also during the $1991 \mathrm{El}$ Niño (mostly anomalous advection). Noteworthy is that zonal SST advection strongly influences the SST decrease during 1992; this is rather similar to what happened in 1988, but no La Niña event occurred in 1992.

Figure 15 shows the dominant expansion coefficients for meridional advection, which represents a larger covariance than zonal advection, $0.70\left({ }^{\circ} \mathrm{C} \text { month }^{-1}\right)^{2}, 66 \%$ of the total squared covariance, but are more poorly correlated $(0.62)$. The two homogeneous covariance maps are again centered in the central and eastern equatorial Pacific, and they are similar in shape and magnitude, except that meridional advection is small just at the equator, as expected, and north of it in the eastern part. The dominant meridional advection mode has a more eastward extension than the zonal one in Figure 14. The spatial domains of influence appear more clearly than in the 

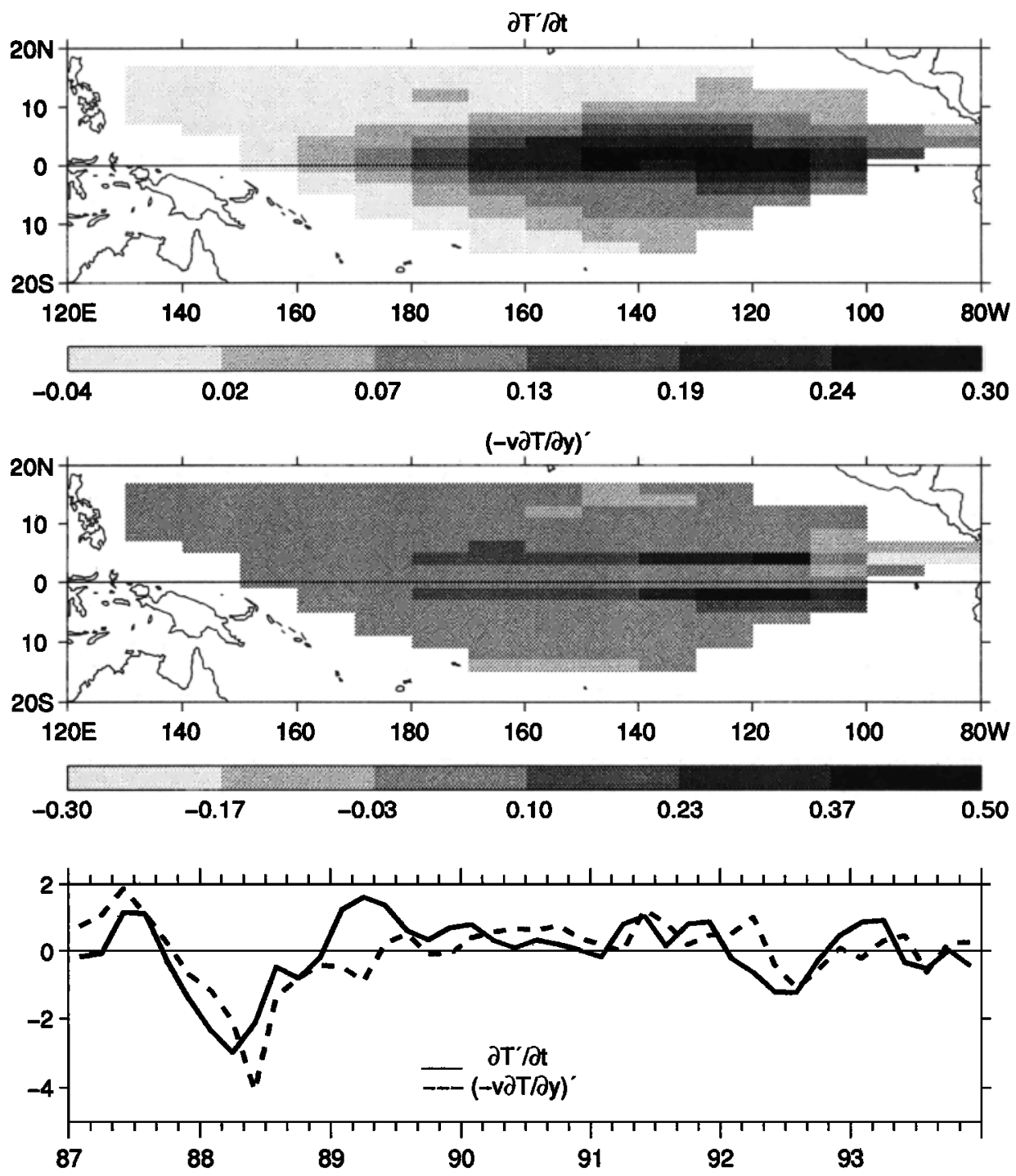

Figure 15. Singular value decomposition of meridional advection effects on SST anomalies. Homogeneous covariance map for the dominant mode of (top) the rate of change of SST anomalies and (middle) minus the meridional advection anomalies. Units are in $\left({ }^{\circ} \mathrm{C} \text { month }{ }^{-1}\right)^{2}$. (bottom) Corresponding normalized time series in solid and dashed lines, respectively. The scale is at left.

correlation analysis, in part, because SVD filters the smallscale noise, but also because it emphasizes covariances. Thus the SVD is undoubtedly suggestive of substantial meridional advection effects. In agreement with our discussion, the expansion coefficients show that meridional advection mostly matters during the $1988 \mathrm{La}$ Niña, but not thereafter. In particular, the meridional advection effects were much smaller in 1992, contrary to the horizontal ones, which were nearly comparable during 1988 and 1992. In fact, repeating the calculation for the period starting in November-December 1988 leads to poorer results and no consistency in the homogeneous covariance maps, even though the sampling was better during the latter period. This stresses the intermittency of the role of meridional advection, contrary to that of zonal advection, which varies less in time.

\section{Summary}

This analysis provides an estimate of the large-scale, lowfrequency current anomalies at depth of $15 \mathrm{~m}$ in the equatorial Pacific between $20^{\circ} \mathrm{N}$ and $20^{\circ} \mathrm{S}$ based on buoy drifts and cur- rent meter records between January 1987 and December 1993. The current anomalies have been calculated with respect to the mean seasonal currents of REV, using objective analysis. The sampling is coarse until mid-1988 but more complete afterward, when the main features of the zonal current anomalies can be documented over much of the domain in a period which includes the end of the 1986-1987 El Niño, the 1988 La Niña, and the 1991-1992 El Niño. The meridional current anomalies are more noisy and have smaller correlation scales, hence they are not as well captured by the data set.

The current anomalies are primarily zonal, with largest amplitudes within about $8^{\circ}$ from the equator and a dominant timescale somewhat smaller than that of the sea surface temperature anomalies. The dominant patterns of variability of the zonal current anomalies are directly linked to ENSO. In particular, broad westward anomaly currents were encountered throughout the equatorial band during the $1988 \mathrm{La}$ Niña, and strong basin-wide eastward anomaly currents persisted from July-August 1991 to January-February 1992, followed by west- 
ward anomaly currents from May-June to July-August 1992. The relations between the anomaly currents and the surface wind stress and other oceanic variables like thermocline depth will be discussed elsewhere.

Using correlation analysis and a singular value decomposition, it was shown that large-scale advection by zonal and meridional currents significantly, but not solely, contributes to the development of sea surface temperature anomalies in the central and, to a lesser extent, the eastern equatorial Pacific. Zonal advection dominates the correlations with the SST anomaly rate of change, while meridional advection tends to dominate the covariances. Both the (seasonally varying) mean advection of SST anomalies and the anomalous advection of the mean SST contribute to the zonal advection effects, while only the (seasonally varying) mean meridional advection of SST anomalies correlates with the SST anomaly rate of change, possibly because of the noise in the meridional current anomaly estimates. Noteworthy is that the meridional SST advection effects are only seen during the $1988 \mathrm{La}$ Niña, while zonal advection effects occur more regularly in time. Still, the analysis stresses the diversity of the ENSO events during the 19871993 period.

Although zonal advection seems more important than meridional advection for the SST anomalies at the resolved spacetime scales, its amplitude is small. This may be due, in part, to the limitation of the data set, in particular, the underestimation of the current anomalies in poorly sampled areas, and also to the good correlation between the fluctuations in zonal current and thermocline depth that is expected from equatorial wave dynamics, making the advection by zonal current anomalies a proxy for more complex effects, like upwelling changes which dominate in the analysis of Kessler and McPhaden [1995]. It will thus be useful to use model data to investigate this problem. Although a detailed comparison with numerical model results has not been done, the present results seem generally consistent with those of Harrison et al. [1990] for the GFDL GCM, who found that anomalous zonal advection played the dominant role in some episodes of large central Pacific SST changes but that other processes, like meridional advection and vertical mixing, were more important during others. On the other hand, the moderate anomalous meridional SST advection estimated here seems inconsistent with the strong one found in the MPI model by Bamett et al. [1991], although a better resolution of the meridional current anomalies may temper this conclusion. Our results suggest, nonetheless, that the simpler ocean models [see Kawabe, 1994; Miller et al., 1993] underestimate the influence of meridional advection and, perhaps, overestimate that of zonal advection. However, the strong smoothing in time that was used here may mask larger zonal advection effects on small timescales. A rigorous comparison with tropical ocean models will be undertaken.

Acknowledgments. The drifters were deployed and the data supplied by M. du Chaffaut, D. Hansen, A. Kartavtseff, H. Ishii, G. McNally, P. Niiler, M. Pazos, Y. du Penhoat, and P. Richardson. The current meter mooring data were provided by the TAO Project Office, directed by M. McPhaden of NOAA/PMEL, and by R. Weisberg. The SST data were provided by R. W. Reynolds. They are all gratefully acknowledged. We would like to thank Elodie Kestenare and Frédéric Salasca, who performed many of the calculations, Laurent Mémery, who provided a first version of the objective analysis program, and Mike McPhaden for his useful comments. This research was supported at LODYC by grants from the Commission of the European Communities (EPO-0003C and EV4C006) and by the PNEDC. G.R. was supported at LDEO by NSF grant OCE-90-00127 and the NOAA Ocean Consortium award NA37GP0518. Lamont-Doherty contribution 5423.

\section{References}

Barnett, T. P., M. Latif, E. Kirk, and E Roeckner, On ENSO physics, J. Clim., 4, 487-515, 1991.

Bretherton, C. S., C. Smith, and J. M. Wallace, An intercomparison of methods for finding coupled patterns in climate data, J. Clim., 5, 541-560, 1992.

Bretherton, F. P., R. E. Davis, and C. B. Fandry, A technique for objective analysis and design of oceanographic experiments applied to MODE-73, Deep Sea Res., 23, 559-582, 1976.

Delcroix, T., J. Picaut, and G. Eldin, Equatorial Kelvin and Rossby waves evidenced in the Pacific Ocean through Geosat sea level and surface current anomalies, J. Geophys. Res., 96, 3249-3262, 1991.

Frankignoul, C., C. Duchêne, and M. Cane, A statistical approach to testing equatorial ocean models with observed data, J. Phys. Oceanogr., 19, 1191-1208, 1989.

Gill, A. E., An estimation of sea-level and surface-current anomalies during the $1972 \mathrm{El} \mathrm{Niño} \mathrm{and} \mathrm{consequent} \mathrm{thermal} \mathrm{effects,} \mathrm{J.} \mathrm{Phys.}$ Oceanogr., 13, 1332-1338, 1983.

Halpern, D., Observations of annual and El Niño flow variations at $0^{\circ}$, $110^{\circ} \mathrm{W}$ and $0^{\circ}, 95^{\circ} \mathrm{W}$ during 1980-1985, J. Geophys. Res., 92, 8197$8212,1987$.

Halpern, D., R. A. Knox, and D. S. Luther, Observations of 20-day period meridional current oscillations in the upper ocean along the Pacific equator, J. Phys. Oceanogr., 18, 1514-1534, 1988.

Hansen, D. V., and A. Herman, Temporal sampling requirements for surface drifting buoys in the tropical Pacific, J. Atmos. Oceanic Technol., 6, 599-607, 1989.

Harrison, D. E., and P. S. Schopf, Kelvin-wave induced anomalous advection and the onset of surface warming in El Niño events, Mon. Weather Rev., 112, 923-933, 1984.

Harrison, D. E., B. S. Giese, and E. S. Sarachick, Mechanisms of SST changes in the equatorial waveguide during the 1982-1983 ENSO, $J$. Clim., 3, 173-188, 1990.

Hayes, S. P., L. J. Mangum, J. Picaut, A. Sumi, and K. Takeuchi, TOGA-TAO: a moored array for real-time measurements in the tropical Pacific Ocean, Bull. Am. Meteorol. Soc., 72, 339-347, 1991 a.

Hayes, S. P., P. Chang, and M. J. McPhaden, Variability of the sea surface temperature in the eastern equatorial Pacific during 19861988, J. Geophys. Res., 96, 10,553-10,566, 1991b.

Kawabe, M., Mechanisms of interannual variations of equatorial sea level associated with ENSO, J. Phys. Oceanogr., 24, 979-993, 1994.

Kessler, W. S., and M. J. McPhaden, The 1991-93 El Niño in the central Pacific, Deep Sea Res., Part II, 42, 295-334, 1995.

Kessler, W. S., and B. A. Taft, Dynamic heights and zonal geostrophic transports in the central tropical Pacific during 1979-1984, J. Phys. Oceanogr., 17, 97-122, 1987.

Legler, D., and J. J. O'Brien, Atlas of tropical wind stress climatology 1971-1980, 187 pp., Fla. State Univ., Tallahassee, 1985.

Lukas, R., E. Firing, P. Hacker, P. L. Richardson, C. A. Collins, R. Fine, and R. Gammon, Observations of the Mindanao current during the western equatorial Pacific Ocean circulation study, $J$. Geophys. Res., 96, 7079-7104, 1991.

McCarty, M. E., and M. J. McPhaden, Mean seasonal cycles and interannual variations at $0^{\circ}, 165^{\circ} \mathrm{E}$ during $1986-1992$, NOAA Tech. Memo. ERL PMEL-98, 64 pp., Pac. Mar. Environ. Lab., Seattle, Wash., 1993.

McPhaden, M. J., and S. P. Hayes, Variability in the eastern equatorial Pacific Occan during 1986-1988, J. Geophys. Res., 95, 13,195-13,208, 1990.

McPhaden, M. J., and M. E. McCarty, Mean seasonal cycles and interannual variations at $0^{\circ}, 110^{\circ} \mathrm{W}$ and $0^{\circ}, 140^{\circ} \mathrm{W}$ during $1980-1991$, NOAA Tech. Memo. ERL PMEL-95, 118 pp., Pac. Mar. Environ. Lab., Seattle, Wash., 1992.

McPhaden, M. J., and J. Picaut, El Niño-Southern Oscillation displacements of the western equatorial Pacific warm pool, Science, 250, 1385-1388, 1990.

McPhaden, M. J., S. P. Hayes, L. J. Mangum, and J. M. Toole, Variability in the western equatorial Pacific Ocean during the 1986-1987 El Niño/Southern Oscillation event, J. Phys. Oceanogr., 20, 190-208, 1990.

Meyers, G., H. Phillips, N. Smith, and J. Sprintall, Space and time 
scales for optimal interpolation of temperature Tropical Pacific ocean, Prog. Oceanogr., 28, 189-218, 1991.

Miller, A. J., T. P. Barnett, and N. E. Graham, A comparison of some tropical ocean models: Hindcast skill and El Niño evolution, J. Phys. Oceanogr., 23, 1567-1591, 1993.

Niiler, P. P., R. E. Davis, and H. J. White, Water-following characteristics of a mixed layer drifter, Deep Sea Res., Part A, 34, 1867-1882, 1987.

Picaut, J., and T. Delcroix, Equatorial wave sequence associated with warm pool displacements during the 1986-1989 El Niño-La Niña, J. Geophys. Res., 100, 18,393-18,408, 1995.

Picaut, J., and R. Tournier, Monitoring the 1979-1985 equatorial Pacific current transports with expendable bathythermograph data, J. Geophys. Res., 96, 3263-3277, 1991.

Poulain, P. M., Estimate of horizontal divergence and vertical velocity in the equatorial Pacific, J. Phys. Oceanogr., 23, 601-607, 1993.

Reverdin, G., C. Frankignoul, E. Kestenare, and M. J. McPhaden, Seasonal variability in the surface currents of the equatorial Pacific, J. Geophys. Res., 99, 20,323-20,344, 1994.

Reynolds, R. W., and T. M. Smith, Improved global sea surface temperature analyses using optimum interpolation, J. Clim., 7, 929-948, 1994.

Seager, R., Modeling tropical Pacific sea surface temperature: 19701987, J. Phys. Oceanogr., 19, 434-443, 1989.
Taft, B. A., and W. S. Kessler, Variations of zonal currents in the central tropical Pacific during 1970 to 1987: Sea level and dynamic height measurements, J. Geophys. Res., 96, 12,599-12,618, 1991.

White, W. B., G. Meyers, and K. Hasunuma, Space/time statistics of short-term climatic variability in the western north Pacific, J. Geophys. Res., 87, 1979-1989, 1982.

Wijffels, S., E. Firing, and H. Bryden, Direct observations of the Ekman balance at $10^{\circ} \mathrm{N}$ in the Pacific, J. Phys. Oceanogr., 24, 1666$1679,1994$.

Wyrtki, K., Equatorial currents in the Pacific 1950 to 1970 and their relation to the trade winds, J. Phys. Oceanogr., 4, 372-380, 1974.

F. Bonjean and C. Frankignoul, Laboratoire d'Océanographie Dynamique et de Climatologie, Unité mixte de recherche CNRSORSTOM-uPMC, Université Pierre et Marie Curie, 4 place Jussieu, 75005 Paris, France.

G. Reverdin, Centre National de la Recherche Scientifique, Group de Recherches de Géodésie Spatiale, UMR 39, 18 av. E. Belin, Toulouse, France.

(Received April 17, 1995; revised October 24, 1995; accepted November 1, 1995.) 